\title{
Airborne mapping of the sub-ice platelet layer under fast ice in McMurdo Sound, Antarctica
}

\author{
Christian Haas ${ }^{1,2,3,4}$, Patricia J. Langhorne ${ }^{5}$, Wolfgang Rack $^{6}$, Greg H. Leonard ${ }^{7}$, Gemma M. Brett ${ }^{6}$, Daniel Price ${ }^{6}$, \\ Justin F. Beckers ${ }^{1,8}$, and Alex J. Gough ${ }^{5}$ \\ ${ }^{1}$ Department of Earth and Atmospheric Science, University of Alberta, Edmonton, Canada \\ ${ }^{2}$ Department of Earth and Space Science and Engineering, York University, Toronto, Canada \\ ${ }^{3}$ Alfred Wegener Institute for Polar and Marine Research, Bremerhaven, Germany \\ ${ }^{4}$ Department of Environmental Physics, University of Bremen, Bremen, Germany \\ ${ }^{5}$ Department of Physics, University of Otago, Dunedin, New Zealand \\ ${ }^{6}$ Gateway Antarctica, University of Canterbury, Christchurch, New Zealand \\ ${ }^{7}$ School of Surveying, University of Otago, Dunedin, New Zealand \\ ${ }^{8}$ Canadian Forest Service, Natural Resources Canada, Edmonton, Canada
}

Correspondence: Christian Haas (chaas@awi.de) and Patricia J. Langhorne (pat.langhorne@otago.ac.nz)

Received: 15 September 2020 - Discussion started: 24 September 2020

Revised: 25 November 2020 - Accepted: 2 December 2020 - Published: 19 January 2021

\begin{abstract}
Basal melting of ice shelves can result in the outflow of supercooled ice shelf water, which can lead to the formation of a sub-ice platelet layer (SIPL) below adjacent sea ice. McMurdo Sound, located in the southern Ross Sea, Antarctica, is well known for the occurrence of a SIPL linked to ice shelf water outflow from under the McMurdo Ice Shelf. Airborne, single-frequency, frequency-domain electromagnetic induction (AEM) surveys were performed in November of 2009, 2011, 2013, 2016, and 2017 to map the thickness and spatial distribution of the landfast sea ice and underlying porous SIPL. We developed a simple method to retrieve the thickness of the consolidated ice and SIPL from the EM in-phase and quadrature components, supported by EM forward modelling and calibrated and validated by drill-hole measurements. Linear regression of EM in-phase measurements of apparent SIPL thickness and drill-hole measurements of "true" SIPL thickness yields a scaling factor of 0.3 to 0.4 and rms error of $0.47 \mathrm{~m}$. EM forward modelling suggests that this corresponds to SIPL conductivities between 900 and $1800 \mathrm{mS} \mathrm{m}^{-1}$, with associated SIPL solid fractions between 0.09 and 0.47 . The AEM surveys showed the spatial distribution and thickness of the SIPL well, with SIPL thicknesses of up to $8 \mathrm{~m}$ near the ice shelf front. They indicate interannual SIPL thickness variability of up to $2 \mathrm{~m}$. In addition, they reveal high-resolution spatial information about the
\end{abstract}

small-scale SIPL thickness variability and indicate the presence of persistent peaks in SIPL thickness that may be linked to the geometry of the outflow from under the ice shelf.

\section{Introduction}

McMurdo Sound is an approximately $55 \mathrm{~km}$ wide sound in the southern Ross Sea, Antarctica, located between Ross Island and the Transantarctic Mountains in Victoria Land (Fig. 1a). It is bordered by the small McMurdo Ice Shelf to the south, a portion of the much larger Ross Ice Shelf. For most of the year, McMurdo Sound is covered by landfast sea ice. The fast ice is mostly composed of first-year ice which usually breaks out during the summer months (Kim et al., 2018). However, in some years some smaller regions of fast ice mostly near the coast or ice shelf edge may persist through one or several summers to form thick multiyear landfast ice. In particular between 2003 and 2011 the southern parts of McMurdo Sound remained permanently covered by thick multiyear ice that had initially formed due to the shelter from swell and currents by the large grounded iceberg B15 further north (Robinson and Williams, 2012; Brunt et al., 2006; Kim et al., 2018). 
McMurdo Sound is characterized by intensive interaction between the ice shelf, sea ice, and ocean (Gow et al., 1998; Smith et al., 2001; Leonard et al., 2011; Robinson et al., 2014; Langhorne et al., 2015). In particular, melting at the base of the Ross and McMurdo ice shelves results in the seasonally variable presence of supercooled ice shelf water (ISW). A plume of supercooled ISW emerges from the McMurdo Ice Shelf and spreads north (Leonard et al., 2011; Robinson et al., 2014), leading to the widespread formation and accumulation of frazil ice to form a sub-ice platelet layer under the fast ice (Fig. 1). This sub-ice platelet layer (SIPL) is a poorly consolidated, highly porous layer of millimetre- to decimetre-scale planar ice crystals (Hoppmann et al., 2020) and is an important contributor to the sea ice mass balance in McMurdo Sound and along the coast of Antarctica in general (Smith et al., 2001; Gough et al., 2012; Langhorne et al., 2015). Its presence and thickness are important indicators of the occurrence of ISW near the ocean surface (Lewis and Perkin, 1985). Subsequently, the SIPL may consolidate and become incorporated into the solid sea ice cover to form so-called incorporated platelet ice (Gow et al., 1998; Smith et al., 2001; Hoppmann et al., 2020). Due to the contributions of platelet ice, sea ice thicknesses in Antarctic near-shore environments can be larger than in the pack ice zone further offshore (Gough et al., 2012).

The SIPL in McMurdo Sound, its dependence on ocean processes, and its role in increasing sea ice freeboard and thickness has been extensively studied for many years (e.g. Gow et al., 1998; Mahoney et al., 2011; Robinson et al., 2014; Price et al., 2014; Langhorne et al., 2015; Brett et al., 2020). The spatial distribution of supercooled water and platelet ice has been observed by means of local water conductivity, temperature, and depth (CTD) measurements and drill-hole measurements on the fast ice (e.g. Lewis and Perkin, 1985; Barry 1988; Dempsey et al., 2010; Leonard et al., 2011; Mahoney et al., 2011; Robinson et al., 2014; Langhorne et al., 2015). These studies showed that a SIPL primarily occurs in a 20 to $30 \mathrm{~km}$ wide, 40 to $80 \mathrm{~km}$ long region extending from the northern tip of the McMurdo Ice Shelf in a northwesterly direction (Fig. 1) and locally near the coast of Ross Island. Drill-hole measurements showed that at the end of the winter the thickness of the SIPL under first-year ice can be up to $7.5 \mathrm{~m}$ (Price et al., 2014; Hughes et al., 2014), coinciding with more than $2.5 \mathrm{~m}$ of consolidated sea ice. With multiyear ice, SIPL and consolidated ice thicknesses can be much larger, depending on location and increasing with age.

Electromagnetic induction sounding (EM) measurements are sensitive to the presence of layers of different electrical conductivity in the subsurface. The presence and thickness of the porous, seawater-saturated SIPL can be retrieved because its electrical conductivity is in between that of the resistive, consolidated sea ice above and the conductive seawater below. The technical and logistical difficulties of on-ice and drill-hole measurements often only allow discontinuous, widely spaced sampling. Therefore observations of the kilometre scale and interannual variability of SIPL occurrence and thickness are still rare or restricted to regions that are accessible by on-ice vehicles (Hoppmann et al., 2015; Hunkeler et al., 2015a, b; Brett et al., 2020). Notably Hunkeler et al. (2015a, b), Irvin (2018), and Brett et al. (2020) have already demonstrated the capability of ground-based, singlefrequency and multifrequency EM measurements to map the occurrence and thickness of the SIPL, using numerical inversion methods. The two latter studies have successfully reproduced the geometry of the SIPL known from earlier studies (Barry, 1988; Dempsey et al., 2010; Langhorne et al., 2015). Using 4 years of ground-based EM data, Brett et al. (2020) have studied the interannual SIPL variability and found that the SIPL was thicker in 2011 and 2017 than in 2013 and 2016 , in close relation to nearby polynya activity that contributes to variations in ocean circulation under the ice shelf. In spite of progress, details are lacking and the processes involved in the outflow of ISW from under the McMurdo Ice Shelf are still little known.

In contrast to ground-based EM measurements where the instrument height over the snow or ice surface is constant, instrument height varies significantly with AEM measurements due to unavoidable altitude variations of the survey aircraft. This makes the application of numerical inversion methods more complicated. Further, the development and calibration of the empirical AEM SIPL retrieval algorithm requires that the electrical conductivity of the SIPL is known. The SIPL is an open matrix of loosely coupled crystals in approximately random orientations, and its conductivity depends on its solid fraction $\beta$ (e.g. Gough et al., 2012; Langhorne et al., 2015), both of which are hard to measure directly. Observations and modelling over the past 4 decades suggest that $\beta$ is quite low, with a mean of $\beta=0.25 \pm 0.09$ (Langhorne et al., 2015) and range of 0.15-0.45 (e.g. Hoppmann et al., 2020).

In this paper we develop a simple empirical algorithm for the joint retrieval of SIPL and consolidated ice thicknesses from single-frequency AEM measurements that is supported by an EM forward model and calibrated and validated by coincident drill-hole measurements. We show that the SIPL conductivity, and therefore its porosity or solid fraction, can be obtained as a first step in the calibration of the method with drill-hole data. We apply this algorithm to five surveys carried out in November of 2009, 2011, 2013, 2016, and 2017 by helicopter and fixed-wing aircraft. Using these techniques we demonstrate the ability of airborne electromagnetic induction (AEM) measurements to map the small-scale distribution of the SIPL under landfast sea ice with high spatial resolution. We apply AEM to study the interannual variability of the SIPL in McMurdo Sound from which we infer some previously unknown features of the ISW plume. 


\section{Methods and measurements}

\subsection{AEM thickness surveys}

All measurements presented here were performed with a towed EM instrument (EM Bird) suspended below a helicopter or fixed-wing airplane and are thus named airborne EM (AEM) surveys. The EM Bird was flown with an average speed of 80 to 120 knots at mean heights of $16 \mathrm{~m}$ above the ice surface (Haas et al., 2009, 2010). The instrument operated in vertical dipole mode with a signal frequency of $4060 \mathrm{~Hz}$ and a spacing of $2.77 \mathrm{~m}$ between transmitting and receiving coils (Haas et al., 2009). The sampling frequency was $10 \mathrm{~Hz}$, corresponding to samples every 5 to $6 \mathrm{~m}$ depending on flying speed. A Riegl LD90 laser altimeter was used to measure the Bird's height above the ice surface, with a range accuracy of $\pm 0.025 \mathrm{~m}$. Positioning information was obtained with a Novatel OEM2 differential GPS with a position accuracy of $3 \mathrm{~m}$ (Rack et al., 2013). Details of EM ice thickness sounding are explained in the following sections.

We have carried out five surveys over the fast ice in McMurdo Sound, in November of 2009, 2011, 2013, 2016, and 2017 (Fig. 1), i.e. in the end of winter when ice thickness was near its maximum. The surveys covered several eastwest-oriented profiles across the sound, as closely as possible from shore to shore, with approximate lengths of $50 \mathrm{~km}$. Although the exact number of profiles differed every year due to weather restrictions, ice conditions, or technical issues, we have attempted to cover the same profiles every year and to collocate them with drill-hole measurements (Sect. 2.2). The profiles repeated most often were located at latitudes of $77^{\circ} 40^{\prime}, 77^{\circ} 43^{\prime}, 77^{\circ} 46^{\prime}$, and $77^{\circ} 50^{\prime}$ S, i.e. 5.5 to $7.4 \mathrm{~km}$ apart (Fig. 1).

EM ice thickness measurements are affected by averaging within the footprint of the instrument, which results in the underestimation of maximum pressure ridge thicknesses (e.g. Kovacs et al., 1995). However, the fast ice in McMurdo Sound is mostly undeformed and level. Over such level ice without an underlying SIPL the agreement of EM thickness estimates is within $\pm 0.1 \mathrm{~m}$ of drill-hole measurements (Pfaffling et al., 2007; Haas et al., 2009). McMurdo Sound therefore presents ideal conditions for EM ice thickness measurements, and the levelness of the ice allows the application of low-pass filtering to remove occasional noise from EMI interference or episodic electronic drift that affects measurements over thick ice without losing significant information on larger scales. Here, we have applied a running-window, 300-point median filter corresponding to a width of 1.5 to $1.8 \mathrm{~km}$ to all data unless mentioned otherwise.

However, the accuracy of $0.1 \mathrm{~m}$ stated above relies on accurate calibration of the EM sensor, which is typically achieved by flying over short sections of open water (Haas et al., 2009). Unfortunately open water overflights were not possible with the helicopter surveys between 2009 and 2013, due to safety regulations. Then the calibration could only be validated over drill-hole measurements and may be less accurate than reported above. Only in 2017 were we able to use a Basler B67 airplane, permitting flights over the open water in the McMurdo Sound polynya which provided ideal calibration conditions (Fig. 1f).

\subsubsection{EM response to sea ice thickness and a sub-ice platelet layer}

Frequency-domain, electromagnetic induction (EM) sea ice thickness measurements rely on the active transmission of a continuous, low-frequency "primary" EM field of one or multiple constant frequencies, penetrating through the resistive snow and ice into the conductive seawater underneath. As the resistivity of cold sea ice and dry snow are approximately infinite (Kovacs and Morey, 1991; Haas et al., 1997), eddy currents are only induced in the seawater underneath. These eddy currents generate a "secondary" EM field with the same frequency as the primary EM field, but with a different amplitude and phase. The EM sensor measures the amplitude and phase of the secondary field, relative to those of the primary field, in units of parts per million (ppm) of the primary field. Amplitude and phase of the complex secondary field are usually decomposed into real and imaginary signal components, called in phase $(I)$ and quadrature $(Q)$, respectively.

$$
\begin{aligned}
& I[\mathrm{ppm}]=\text { Amplitude }[\mathrm{ppm}] \times \cos \left(\text { Phase }\left[{ }^{\circ}\right]\right) \\
& Q[\mathrm{ppm}]=\text { Amplitude }[\mathrm{ppm}] \times \sin \left(\text { Phase }\left[{ }^{\circ}\right]\right)
\end{aligned}
$$

With negligible sea ice and snow conductivities, measured $I$ and $Q$ of the relative secondary field depend on the distance between the EM instrument and the ice-water interface and on the conductivity of the seawater. With known seawater conductivity, $I$ and $Q$ decay as an approximate negative exponential with increasing distance $\left(h_{0}+h_{\mathrm{i}}\right)$ between the EM instrument and the ice-water interface, where $h_{0}$ is instrument height above the ice and $h_{\mathrm{i}}$ is ice thickness (see Sect. 2.1.3 below; Haas, 2006; Pfaffling et al., 2007; Haas et al., 2009):

$I \approx c_{0} \times \exp \left(-c_{1} \times\left(h_{0}+h_{\mathrm{i}}\right)\right)$,
$Q \approx c_{2} \times \exp \left(-c_{3} \times\left(h_{0}+h_{\mathrm{i}}\right)\right)$,

with constants $c_{0 . .3}$. Then, height above the ice-water interface can be obtained independently from both $I$ and $Q$ from equations of the form

$$
\left(h_{0}+h_{\mathrm{i}}\right) \approx-1 / c_{1} \times \ln \left(I / c_{0}\right)
$$

or

$\left(h_{0}+h_{\mathrm{i}}\right) \approx-1 / c_{3} \times \ln \left(Q / c_{2}\right)$.

For ground-based measurements with an EM instrument located on the snow or ice surface (i.e. $h_{0}=0 \mathrm{~m}$ ), the 
distance to the ice-water interface corresponds to the total (snow-plus-ice) thickness $h_{\mathrm{i}}$ (Kovacs and Morey, 1991; Haas et al., 1997). With airborne measurements, the variable height of the EM instrument above the snow or ice surface $h_{0}$ is measured with a laser altimeter. Then, total (ice-plussnow) thickness is computed from the difference between the electromagnetically derived height above the ice-water interface and the laser-determined height above the snow or ice surface:

$h_{\mathrm{i}, I} \approx-1 / c_{1} \times \ln \left(I / c_{0}\right)-h_{0}$

or

$h_{\mathrm{i}, Q} \approx-1 / c_{3} \times \ln \left(Q / c_{2}\right)-h_{0}$

(Pfaffling et al., 2007; Haas et al., 2009). Over typical saline seawater, $I$ (Eq. 1a) is 2 to 3 times larger than $Q$ (Eq. 1b) and has much better signal-to-noise characteristics (Haas, 2006). It is therefore the preferred channel for ice thickness retrievals in the Arctic and Antarctic (Haas et al., 2009). Because snow and ice are indistinguishable for EM measurements due to their low conductivity, no attempt is made here to distinguish between them, and the terms ice thickness and consolidated ice thickness are used throughout to describe total, i.e. snow plus ice, thickness.

\subsubsection{Apparent thickness}

In the case of the presence of a SIPL, ice thickness retrievals become significantly more difficult and will lead to large errors if the effect of the SIPL is not taken into account. Induction in the conductive SIPL results in an additional secondary field which mutually interacts with the secondary field induced in the water underneath. Thus the EM signal becomes a function of both consolidated ice thickness and the thickness and conductivity of the SIPL. The conductivity of the porous SIPL is higher than that of consolidated ice $(\sim 0$ $50 \mathrm{mS} \mathrm{m}^{-1}$; Haas et al., 1997) but most likely lower than that of the seawater underneath (approximately $2700 \mathrm{mS} \mathrm{m}^{-1}$ in McMurdo Sound; e.g. Mahoney et al., 2011; Robinson et al., 2014). Therefore, over consolidated ice underlain by a SIPL, the measured secondary field will be smaller than if there were no SIPL and larger than if the SIPL were consolidated throughout and highly resistive.

Here we introduce the term "apparent thickness", $h_{\mathrm{a}}$, to describe the ice thickness obtained from either $I$ or $Q$ following the standard procedures and simple negative exponential relationship in Eq. (3) (Haas et al., 2009; Rack et al., 2013). This is the thickness that one obtains if the presence of a SIPL was not considered. The apparent thickness $h_{\mathrm{a}}$ agrees with the true thickness $h_{\mathrm{i}}$ if the ice has negligible conductivity. Otherwise, in the presence of a conductive SIPL, the apparent thickness $h_{\mathrm{a}}$ will be more than the consolidated ice thickness, but less than the total, consolidated ice plus SIPL thickness $h_{\mathrm{i}}+h_{\text {sipl }}$. Therefore, using the simple, negative-exponential relation between $I$ or $Q$ and ice thickness described above (Eqs. 1, 3), smaller $I$ and $Q$ due to the presence of a SIPL will result in apparent consolidated ice thickness estimates $h_{\mathrm{a}}$ that are larger than the true consolidated ice thickness $h_{\mathrm{i}}$. However, the derived consolidated ice thickness $h_{\mathrm{a}}$ will be less than the total ice plus SIPL thickness $h_{\mathrm{i}}+h_{\text {sipl }}$ because the thickness retrieval assumes negligible ice conductivity, which is an invalid assumption for the SIPL. Therefore the measured $I$ and $Q$ would be larger than they are for negligible SIPL conductivity.

As will be shown in Sect. 2.1.3, $I$ and $Q$ respond differently to the presence of a SIPL, and Q is in fact little affected and can therefore still be used to retrieve $h_{\mathrm{i}}$. The presence of this layer can therefore be detected by deviations between the apparent thicknesses derived from $I$ and $Q$. The different responses of $I$ and $Q$ can also be used to determine the thickness of the SIPL and thus to convert apparent thickness into consolidated ice and SIPL thicknesses (Sect. 2.1.4). In general, the thickness and conductivity of consolidated ice and the SIPL can be derived by means of full, least-square layered-earth inversion of airborne $I, Q$, and laser altimeter data and by potentially using more signal frequencies (e.g. Rossiter and Holladay, 1994; Pfaffling and Reid, 2009; Hunkeler et al., 2015a, b). However, numerical inversion is computationally demanding and requires wellcalibrated data with good signal-to-noise characteristics. In addition, these algorithms require certain a priori knowledge about the stratigraphy of the ice, i.e. layers present and their conductivities. The development and application of such algorithms is beyond the scope of this paper. Instead, here we apply a simple empirical algorithm for the joint retrieval of SIPL and consolidated ice thicknesses from single-frequency AEM measurements. The following section will outline the theoretical basis for this approach, including results from an EM forward model and a discussion of assumptions that need to be made.

\subsubsection{Modelling EM responses over fast ice with a SIPL}

To demonstrate the sensitivity of EM measurements to the presence of a SIPL, and to evaluate the potential of determining its thickness, we performed extensive one-dimensional forward modelling of the EM response to different SIPL thicknesses and conductivities. The $I$ and $Q$ components of the complex relative secondary field measured with horizontal coplanar coils over $n$ horizontally stratified layers overlying a homogeneous half-space can be calculated as (e.g. Mundry, 1984)

$$
(I+j Q)=r^{2} \int_{0}^{\infty} \lambda^{2} R_{0} e^{-2 \lambda h_{0}} J_{0}(\lambda r) \mathrm{d} \lambda .
$$

This is a so-called Hankel transform utilizing a Bessel function of the first kind of order zero $\left(J_{0}\right)$, with $r$ being the coil spacing, $h_{0}$ the receiver and transmitter height above 
the ice, and $\lambda$ the vertical integration constant. This equation can only be solved numerically using digital filters. Here we used the filter coefficients of Guptasarma and Singh (1997) that are, for example, implemented in a computer program by Irvin (2019). $R_{0}$ is called the transverse electric reflection coefficient and is a recursive function of signal angular frequency $\omega$ and the thickness and electromagnetic properties of individual layers (electrical conductivity $\sigma$ and magnetic permeability $\left.\mu_{0}\right)$ :

$R_{n-1}=K_{n-1}$,

$R_{k-2}=\left(K_{k-2}+R_{k-1} u_{k-1}\right) /\left(1+K_{k-2} R_{k-1} u_{k-1}\right)$,

with

$u_{k}=\exp \left(-2 h_{k} v_{k}\right)$

$v_{k}=\left(\lambda^{2}+j \omega \mu_{0} \sigma_{k}\right)^{1 / 2}$,

$K_{k-1}=\left(v_{k-1}-v_{k}\right) /\left(v_{k-1}+v_{k}\right)$.

In these equations $n$ is the number of layers (four in this paper: non-conductive air, sea ice and snow, SIPL, and seawater), $k=1$ (air), .., 4 (seawater), and $j=\sqrt{(-1)}$. Figure 2 shows the general design of this four-layer case and also the layer properties used for the computations which are based on the typical conditions during our surveys in McMurdo Sound.

As the EM signal is ambiguous for variable layer thicknesses and conductivities, we only calculate signal changes due to variable SIPL (layer 2) thicknesses $h_{\text {sipl }}$ and conductivities $\sigma_{\text {sipl }}$, keeping all other parameters constant and representative of our measurements: we chose instrument height $h_{0}=16 \mathrm{~m}$, sea ice (layer 1) thickness $h_{\mathrm{i}}=2 \mathrm{~m}$ and conductivity $\sigma_{\mathrm{i}}=0 \mathrm{mS} \mathrm{m}^{-1}$, and seawater (layer 3: infinitely deep, homogeneous half-space) conductivity $\sigma_{\mathrm{w}}=$ $2700 \mathrm{mS} \mathrm{m}^{-1}$. SIPL conductivity $\sigma_{\text {sipl }}$ was varied between 0 and $2700 \mathrm{mS} \mathrm{m}^{-1}$ in steps of $300 \mathrm{mS} \mathrm{m}^{-1}$ to study a range of properties between the two extreme cases of negligible and maximum seawater conductivity. SIPL thickness $h_{\text {sipl }}$ was varied from 0 to $20 \mathrm{~m}$ to also include the most extreme potential cases, such as to investigate the EM signal behaviour over potentially thick platelet layers under multiyear ice or an ice shelf. Note that we chose $\sigma_{\mathrm{i}}=0 \mathrm{mS} \mathrm{m}^{-1}$ for simplicity, while in reality consolidated sea ice still contains some brine that can slightly raise its conductivity up to $\sigma_{\mathrm{i}}=50 \mathrm{mS} \mathrm{m}^{-1}$ or so (Haas et al., 1997). However, those small variations have little effect on the EM retrieval of consolidated ice thickness (Haas et al., 1997; 2009).

Figure 3 shows the dependence of $I$ and $Q$ model curves over $2 \mathrm{~m}$ thick consolidated ice on variable SIPL thickness and conductivity obtained using the model of Eq. (4). As expected it can be seen that $I$ and $Q$ do not change with increasing SIPL thickness if the SIPL conductivity is $2700 \mathrm{mS} \mathrm{m}^{-1}$, i.e. if the SIPL is indistinguishable from seawater. I decreases exponentially with increasing SIPL thickness, the effect becoming more pronounced as SIPL conductivity decreases. When SIPL conductivity is $0 \mathrm{mS} \mathrm{m}^{-1}$, i.e. when the
SIPL is indistinguishable from consolidated ice, the resulting curve is identical to measurements over consolidated ice only, i.e. generally following the form of Eq. (1).

In contrast, and not quite intuitively, initially $Q$ changes little with increasing SIPL conductivity and thickness. Indeed, $Q$ even increases slightly with increasing SIPL thickness if the SIPL conductivity is high (e.g. larger than $600 \mathrm{mS} \mathrm{m}^{-1}$ ). Only for very low SIPL conductivity (e.g. below $600 \mathrm{mS} \mathrm{m}^{-1}$ ) does $Q$ decrease strongly, and for a conductivity of $0 \mathrm{mS} \mathrm{m}^{-1}$ the curve is identical to the consolidated ice case, as for $I$. Note that $I$ is generally much larger than $Q$ and that $I$ is more strongly dependent on SIPL thickness. Therefore the sensitivity of $I$ to the presence, thickness, and conductivity of a SIPL is much larger than that of $Q$.

Figure 4 shows the apparent thicknesses, $h_{\mathrm{a}, I}$ and $h_{\mathrm{a}, Q}$, that result from applying Eq. (3a, b) to the $I$ and $Q$ curves in Fig. 3. Equation $(3 a, b)$ correspond to a SIPL conductivity of $0 \mathrm{mS} \mathrm{m}^{-1}$ that would be used if the presence of an SIPL were unknown or ignored. For example, and based on the same reasoning as above, Fig. 4 shows that the apparent thicknesses agree with the total thickness $h_{\mathrm{i}}+h_{\text {sipl }}$ if the SIPL conductivity was zero, i.e. indistinguishable from solid ice. If the conductivity of the SIPL was indistinguishable from that of seawater (i.e. $2700 \mathrm{mS} \mathrm{m}^{-1}$ ), the obtained apparent thicknesses are $2 \mathrm{~m}$, i.e. the thickness of the consolidated ice only. For the in-phase component, Fig. 4a shows that apparent thicknesses for intermediate SIPL conductivities fall in between, with increasing apparent thicknesses with decreasing SIPL conductivities.

In contrast, apparent thicknesses derived from $Q$ (Fig. 4b) are similar to the consolidated ice thickness ( $2 \mathrm{~m}$ in this case) for most SIPL conductivities. Only for SIPL conductivities below $600 \mathrm{mS} \mathrm{m}^{-1}$ are there relatively stronger deviations, and for a SIPL conductivity of $0 \mathrm{mS} \mathrm{m}^{-1}$ the quadraturederived apparent thickness equals the total thickness $h_{\mathrm{i}}+$ $h_{\text {sipl. }}$. In summary these results show that the in-phase signal $I$ responds much more strongly to the presence of a SIPL than the quadrature $Q$.

Note that most in-phase curves level out for large SIPL thicknesses, the effect being exacerbated for higher SIPL conductivities (Fig. 3). This is due to the limited penetration depth of EM fields in highly conductive media. Accordingly the corresponding derived apparent conductivities level out with increasing SIPL thickness as well and are insensitive to further increases in SIPL thickness (Fig. 4a). In practice this means that the EM in-phase signals are only sensitive to SIPL thickness changes up to a certain SIPL thickness and that the sensitivity decreases with increasing SIPL thickness and conductivity. In contrast, while $Q$ is relatively insensitive to the presence and thickness of a SIPL for SIPL conductivities above $600 \mathrm{mS} \mathrm{m}^{-1}$, responses are non-monotonic for low SIPL conductivities and possess local minima at varying SIPL thicknesses. As a result, apparent thicknesses derived from $Q$ possess local maxima at variable SIPL thicknesses. 

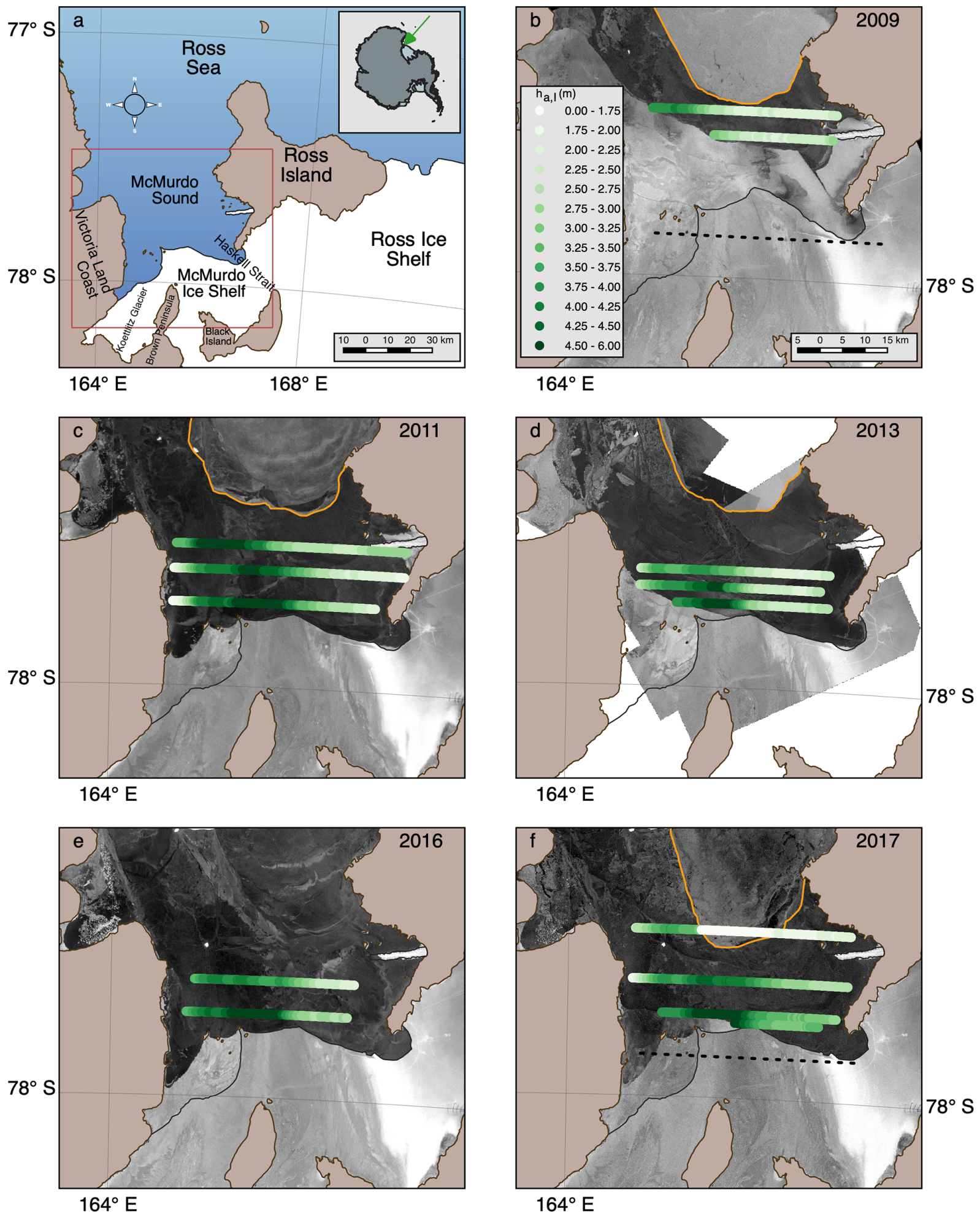

Figure 1. Overview maps of the AEM surveys carried out in 2009, 2011, 2013, 2016, and 2017. (a) Regional overview and the location of McMurdo Sound (green arrow) and boundaries of satellite images (red). (b-f) Locations of east-west profiles, overlaid on syntheticaperture radar (SAR) satellite images to show differences in general ice conditions and ice types (Brett et al., 2020; 2009/11: Envisat; 2013: TerraSAR-X; 2016/17: Sentinel-1). Colours correspond to different apparent ice thicknesses $h_{\mathrm{a}, I}$ (Sect. 2.1.2). Orange lines mark respective fast ice edges. Bright areas to the south are the McMurdo Ice Shelf. Black dashed lines in (b, f) show tracks of ice shelf thickness surveys used in Figs. 10a and 11 (Rack et al., 2013). 


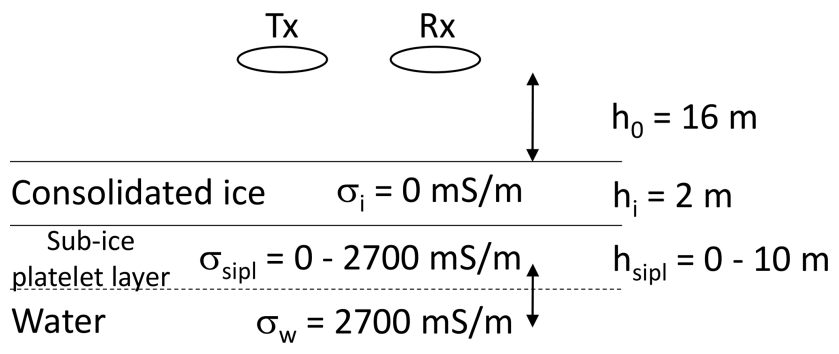

Figure 2. Schematic of the four-layer forward model to compute EM responses over sea ice underlain by a SIPL with variable thickness and conductivity. $T x$ and $R x$ illustrate transmitting and receiving coils, respectively. Instrument height $h_{0}=16 \mathrm{~m}$, snow plus ice thickness $h_{\mathrm{i}}=2 \mathrm{~m}$, and water conductivity of $2700 \mathrm{mS} \mathrm{m}^{-1}$ are based on typical conditions during our surveys in McMurdo Sound.

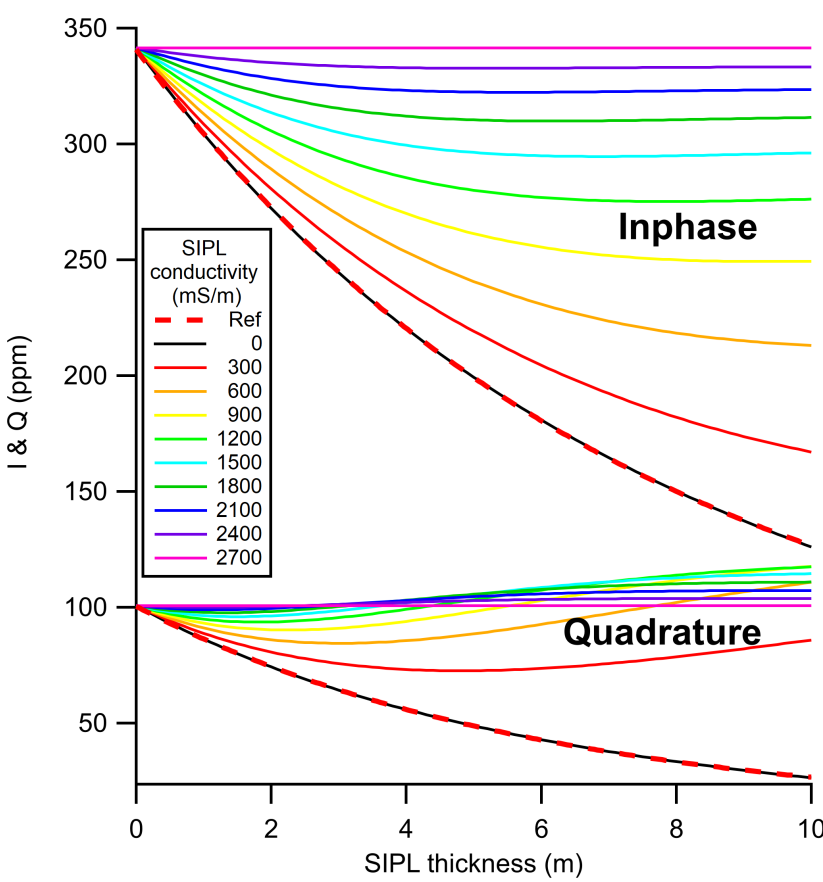

Figure 3. In-phase $I$ and quadrature $Q$ responses to a 0 to $10 \mathrm{~m}$ thick SIPL under $2 \mathrm{~m}$ thick consolidated ice for SIPL conductivities of 0 to $2700 \mathrm{mS} \mathrm{m}^{-1}$ computed with a three-layer EM forward model (see Fig. 2). Ref shows negative exponential curves for consolidated ice with zero conductivity used for computation of $I$ and $Q$ apparent thicknesses using Eq. (2b).

\subsubsection{SIPL and consolidated ice thickness retrieval from measurements of $I$ and $Q$}

The contrasting behaviour of $I$ and $Q$ to variable SIPL thickness and conductivity (Fig. 3) and the resulting contrasting behaviour of the derived apparent thicknesses (Fig. 4) can be used to retrieve SIPL and consolidated ice thicknesses. The figures show that, if we derive apparent thicknesses from both the $I$ and $Q$ measurements independently, the results will agree if there is just consolidated ice under the EM in- strument, and they will disagree if there is a SIPL under the consolidated ice. In general, the disagreement between $h_{\mathrm{a}, Q}$ and $h_{\mathrm{a}, I}$ will be larger the thicker the SIPL is. In other words, the presence and thickness of a SIPL can be retrieved from $I$ and $Q$ measurements, within limits.

Using the behaviour described above, we derive the thickness of the consolidated ice $h_{\mathrm{i}}$ directly from the apparent thickness of the $Q$ measurement $h_{\mathrm{a}, Q}$, as it is mostly insensitive to the presence of a SIPL (Fig. 4b):

$h_{\mathrm{i}}=h_{\mathrm{a}, Q}$.

Then, according to Fig. 4a the apparent thickness derived from the in-phase measurements $h_{\mathrm{a}, I}$ corresponds approximately to the sum of consolidated ice thickness and a fraction $\alpha$ of the true SIPL thickness:

$h_{\mathrm{a}, I}=h_{\mathrm{i}}+\alpha h_{\mathrm{sipl}} \approx h_{\mathrm{a}, Q}+\alpha h_{\mathrm{sipl}}$.

Therefore we can derive $h_{\text {sipl }}$ from

$h_{\text {sipl }}=\left(h_{\mathrm{a}, I}-h_{\mathrm{i}}\right) / \alpha \approx\left(h_{\mathrm{a}, I}-h_{\mathrm{a}, Q}\right) / \alpha$.

The SIPL scaling factor $\alpha$ primarily depends on the SIPL conductivity and governs how much the true SIPL thickness is underestimated (Fig. 4a). The expected range of $\alpha$ values in Eq. (5c) and the uncertainty resulting from Eq. (5a) are shown in Fig. 5.

Figure 5a shows the ratio of apparent thickness $h_{\mathrm{a}}$ over "true" consolidated ice thickness $h_{\mathrm{i}}$ which should be 1 according to Eq. (5a). However, it can be seen that the ratio strongly depends on $h_{\mathrm{i}}$ and SIPL conductivity. In general the ratio is larger than 1 for a thin SIPL and smaller than 1 for a thick SIPL. The deviations from 1 decrease with increasing $h_{\mathrm{i}}$ and with increasing SIPL conductivity. For example, for $h_{\mathrm{i}}=2 \mathrm{~m}$ and a SIPL conductivity of $1200 \mathrm{mS} \mathrm{m}^{-1}$ the ratio first increases to 1.27 and then decreases to a minimum of 0.7 before slowly increasing again (Fig. 5a). This means that with a true consolidated ice thickness of $2 \mathrm{~m}$, typical for end-of-winter first-year fast ice in McMurdo Sound, our method (Eq. 5a) overestimates or underestimates the true consolidated ice thickness by up to $30 \%$. However, the actual uncertainty depends on SIPL thickness and decreases with increasing $h_{\mathrm{i}}$.

Figure 5b shows that $\alpha$ (Eq. 5c) decreases monotonically with increasing SIPL thickness and conductivity. For example, for a SIPL conductivity of $1200 \mathrm{mS} \mathrm{m}^{-1}$ it decreases from a value of 0.55 with no SIPL to values below 0.1 for a very thick SIPL with $h_{\text {sipl }} \gg 15 \mathrm{~m}$. At a SIPL conductivity of $1200 \mathrm{mS} \mathrm{m}^{-1}$ it ranges between $\alpha=0.4$ and 0.3 for SIPL thicknesses between 3.7 and $6.2 \mathrm{~m}$. There is little dependence on consolidated ice thickness $h_{\mathrm{i}}$. These results imply that the uncertainties due to unknown SIPL thickness (the parameter that should actually be derived from this procedure) and SIPL conductivity can be quite large. This is because of the increasingly limited sensitivity of the AEM measurements to increasing SIPL thicknesses discussed above with regard to Fig. 4a and penetration depth. 


\subsection{Drill-hole validation measurements}

At 55 sites over all 5 years of observation, drill-hole measurements were performed under the flight tracks of the EM Bird to measure the thickness of snow, sea ice, and the SIPL, and the freeboard of the ice. The protocol at each drill site has been described in Price et al. (2014) and Hughes et al. (2014). At each site, five measurements were made at the centre and corners of a $30 \mathrm{~m}$ wide "cross". Sea ice thickness and the depth of the bottom of the sub-ice platelet layer were measured with a classical T-bar at the end of a tape measure lowered through the ice and pulled up until resistance was felt (Haas and Druckenmiller, 2009; Gough et al., 2012). This is an established method in the absence of a sub-ice platelet layer, with ice thickness accuracies of 2 to $5 \mathrm{~cm}$. However, the bottom of the unconsolidated sub-ice platelet layer is often fragile and may be gradual, such that pull resistance may only increase gradually and may be difficult to feel (Gough et al., 2012). This is further complicated by the frequent presence of ice platelets inside the drill hole causing additional resistance and impeding detection of the water level within the hole. Ice crystals may be jammed between the Tanchor and the bottom of the consolidated ice, hampering the accurate determination of sea ice thickness. Following Price et al. (2014), we assume typical relative errors (1 standard deviation) for the drill-hole sea ice and sub-ice platelet layer thicknesses to be $\pm 2 \%$ and $\pm 5 \%$ to $30 \%$, respectively. Snow thickness was measured on the cross lines at $0.5 \mathrm{~m}$ intervals using a ruler $(2009,2011$, and 2013) or a Magnaprobe (2016 and 2017; Sturm and Holmgren, 2018). Throughout this paper we have added snow and ice thickness to comprise total consolidated ice thickness $h_{\mathrm{i}}$.

\section{Results}

\subsection{Apparent ice thicknesses in McMurdo Sound}

The SAR images in Fig. 1b-f show that the fast ice in McMurdo Sound can be quite variable, with regard to both the location of the ice edge and the types of first-year ice that are present (Brett et al., 2020). Due to break-up events during the winter there can be refrozen leads with younger and thinner ice, or larger areas of thinner ice, as can for example be seen in 2013 in the northeast of the panel. These variable ice conditions result in variable thickness profiles that are indistinguishable from small undulations due to instrument drift. The SAR images also show the presence of multiyear landfast ice in some years, in particular in 2009. The multiyear ice is much thicker than the first-year ice, and we have few drill-hole measurements there. Therefore, results over multiyear ice are not included here.

Figures $1 \mathrm{~b}-\mathrm{f}$ also show the apparent thickness $h_{\mathrm{a}, I}$ determined from the in-phase component along the profiles. In general it can be seen that $h_{\mathrm{a}, I}$ ranges between 2.0 and
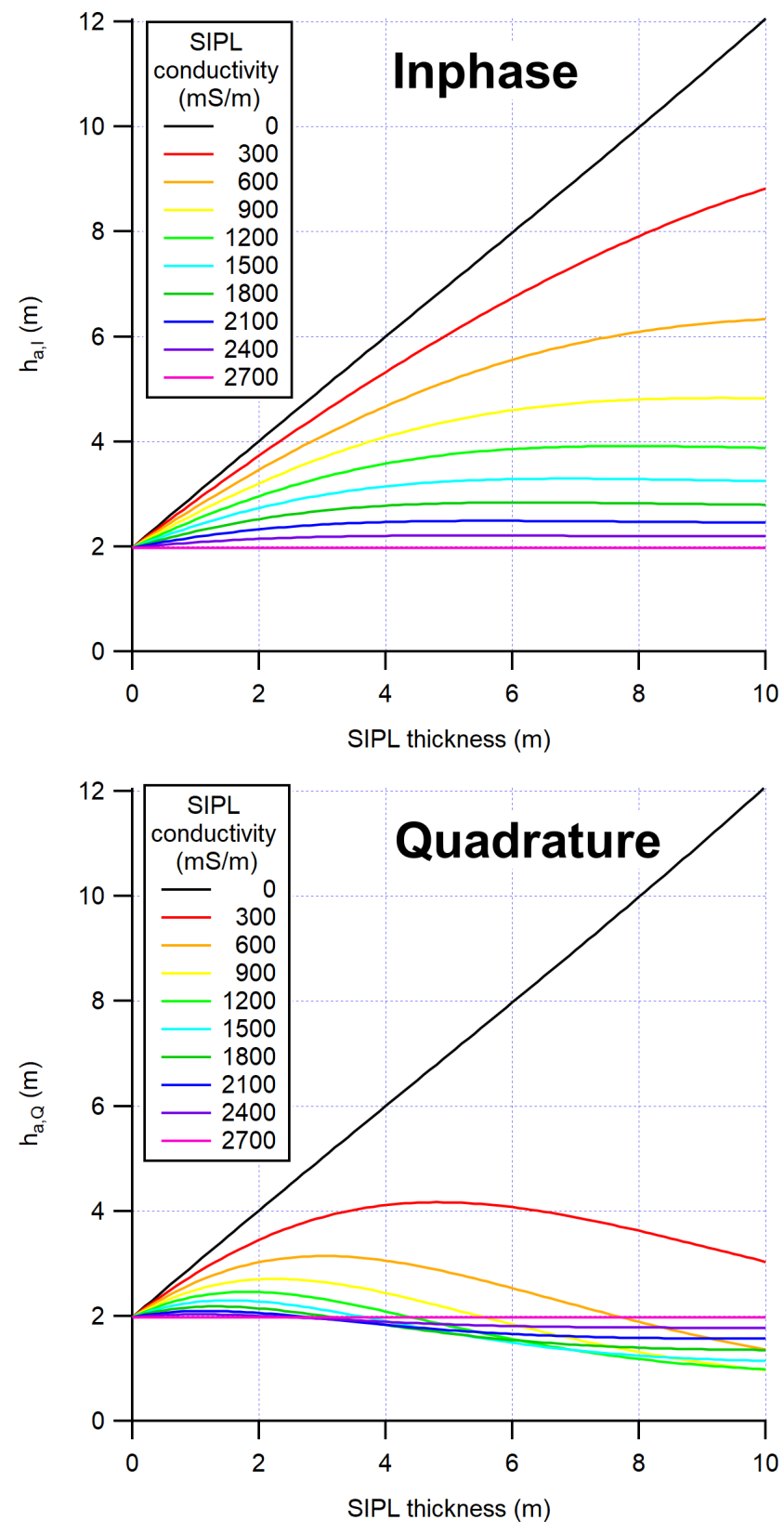

Figure 4. Apparent thicknesses resulting from applying simple negative-exponential equations like in Eq. $(3 \mathrm{a}, \mathrm{b})$ to the $I$ and $Q$ curves in Fig. 3.

$2.5 \mathrm{~m}$, in the eastern side of the sound, in good agreement with other studies (Price et al., 2014, Brett et al., 2020) and with our drill-hole measurements (see below). On the western side of the sound much thicker ice, up to $6 \mathrm{~m}$ in apparent thickness, can be seen. The regional distribution and thickness of this thick ice coincides with our general knowledge of the distribution of the ISW plume and the SIPL in the region (Dempsey et al., 2010; Langhorne et al., 2015). In particular, the data show that apparent ice thicknesses are much larger near the ice shelf than farther north, in agreement with 

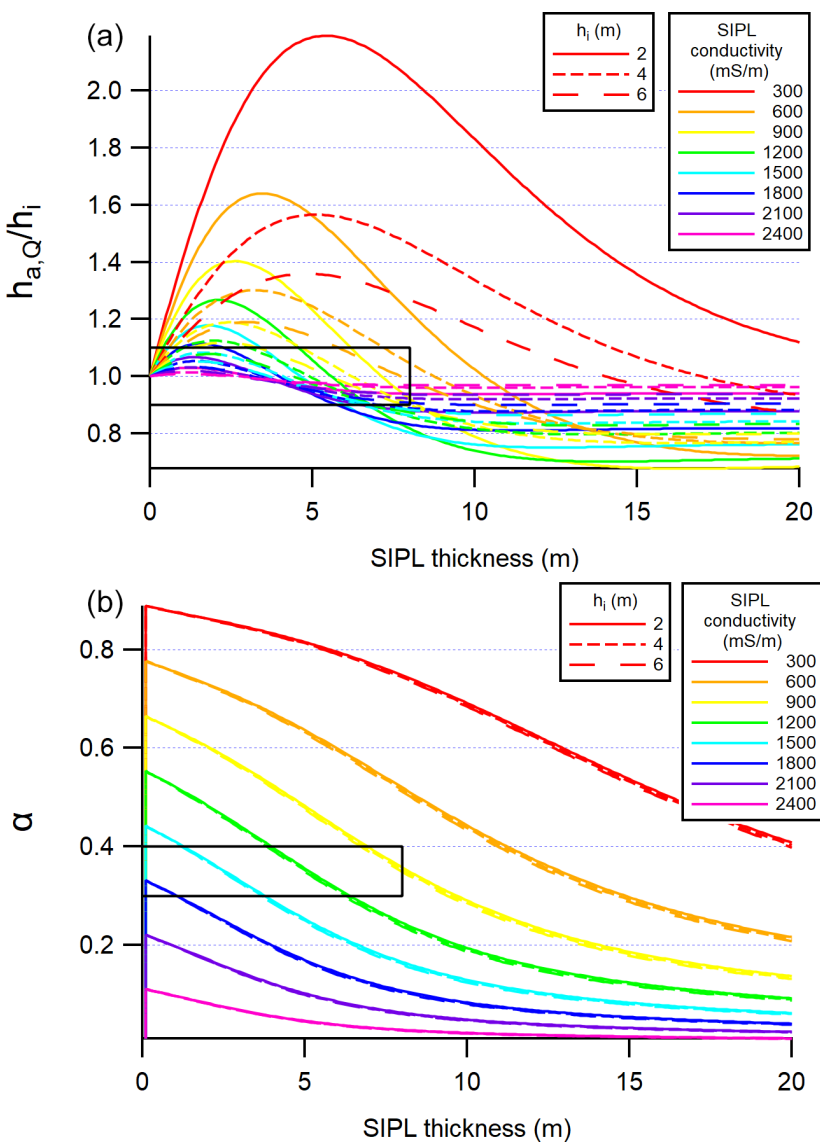

Figure 5. Ratio of $h_{\mathrm{a}, Q} / h_{\mathrm{i}}$ (a; see Eq. 5a) and $\alpha=\left(h_{\mathrm{a}, I}-h_{\mathrm{i}}\right) / h_{\text {sipl }}$ (b; see Eq. 5c) vs. SIPL thickness, at different consolidated ice thicknesses $h_{i}$ between 2 and $6 \mathrm{~m}$ and different SIPL conductivities between 300 and $2400 \mathrm{mS} \mathrm{m}^{-1}$. Curves follow from curves in Figs. 3 and 4. Black boxes show the range of $h_{\mathrm{a}, Q} / h_{\mathrm{i}}$ and $\alpha$ values resulting from the calibration (Sect. 3.2).

the fact that the ISW plume emerges from the ice shelf and then spreads north. However, the obtained apparent thicknesses are much smaller than what is known from drill-hole measurements, when SIPL thickness is taken into account. These results confirm the results of our modelling study and demonstrate that the in-phase measurements are sensitive to the presence and thickness of a SIPL.

In general, apparent thicknesses $h_{\mathrm{a}, Q}$ derived from the quadrature measurements show much less variability. We will present them below where we show the derived consolidated ice thicknesses (Sect. 3.2, Fig. 6).

\subsection{Calibration of consolidated ice and SIPL thickness}

The behaviour of $h_{\mathrm{a}, Q}$ and $h_{\mathrm{a}, I}$ can be seen much better when vertical cross sections of individual profiles are plotted. This is shown in Fig. 6 for one profile near the ice shelf edge (Fig. 6a) and one farther north (Fig. 6b). The figure also shows drill-hole data for comparison. Note that here and in
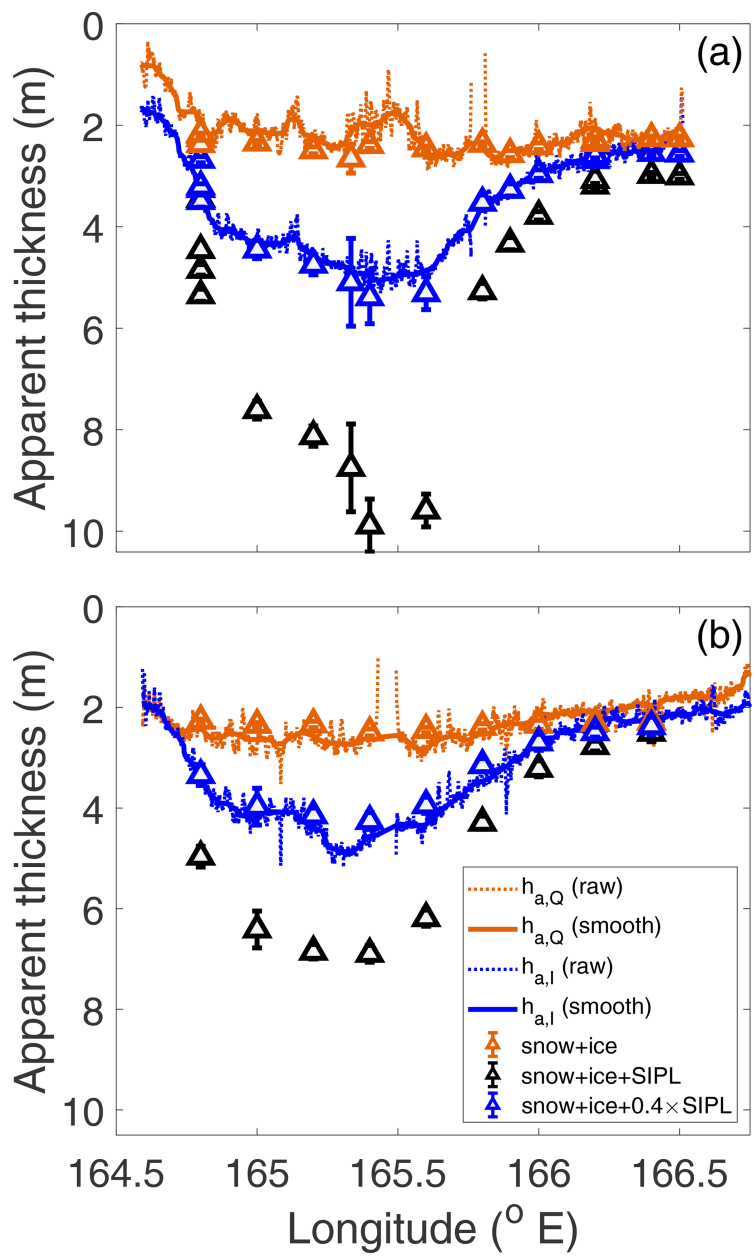

Figure 6. Apparent AEM thicknesses $h_{\mathrm{a}, Q}$ (orange lines) and $h_{\mathrm{a}, I}$ (blue lines) along E-W profiles at (a) $77^{\circ} 50^{\prime} \mathrm{S}$ and (b) $77^{\circ} 46^{\prime} \mathrm{S}$ in November 2011, approximately 3 and $11 \mathrm{~km}$ from front of McMurdo Ice Shelf, respectively. Dotted lines are raw data, while solid lines are filtered with a 300-point median filter. Triangles show mean and standard deviation of drill-hole measurements at calibration points. Consolidated ice (snow plus ice; orange), consolidated ice plus SIPL thickness (black), and consolidated ice plus $(\alpha=0.4) \times$ SIPL thickness (blue; Eq. 5c).

Fig. 9 we plotted thickness downwards to illustrate more intuitively the bottom of the consolidated ice and SIPL. It can be seen that $h_{\mathrm{a}, Q}$ and $h_{\mathrm{a}, I}$ agree with each other quite well in the east (right) and show an ice thickness of approximately 2.0 to $2.5 \mathrm{~m}$, in agreement with the consolidated ice thickness in that region. However, farther west (left), in the region of the ISW plume and thicker SIPL, the curves deviate from each other. While $h_{\mathrm{a}, Q}$ changes relatively little, $h_{\mathrm{a}, I}$ increases strongly. The curves join again in the farthest west, where the ISW plume is known to vanish (Robinson et al., 2014). While both curves follow the expected behaviour resulting from the model results well (Sect. 2.1.3), and while $h_{\mathrm{a}, Q}$ is in reasonable agreement with the drill-hole measure- 
Table 1. Summary of drill-hole calibration results showing the number of drill-hole measurements $N$, derived scaling factor $\alpha$ (Eq. 5c), SIPL conductivity $\sigma_{\mathrm{SIPL}}$, and solid fraction $\beta$. Data from several years with similar behaviour were pooled to increase the number of data points for more reliable fits.

\begin{tabular}{lrrrr}
\hline Year (November) & $N$ & $\alpha(95 \%$ conf. int. $)$ & $\sigma_{\text {SIPL }}\left(\mathrm{mS} \mathrm{m}^{-1}\right)$ & $\beta$ \\
\hline 2009,2011 and 2017 & 46 & $0.40 \pm 0.07$ & $900-1500$ & $0.16-0.47$ \\
2013 and 2016 & 9 & $0.30 \pm 0.15$ & $1000-1800$ & $0.09-0.43$ \\
\hline
\end{tabular}

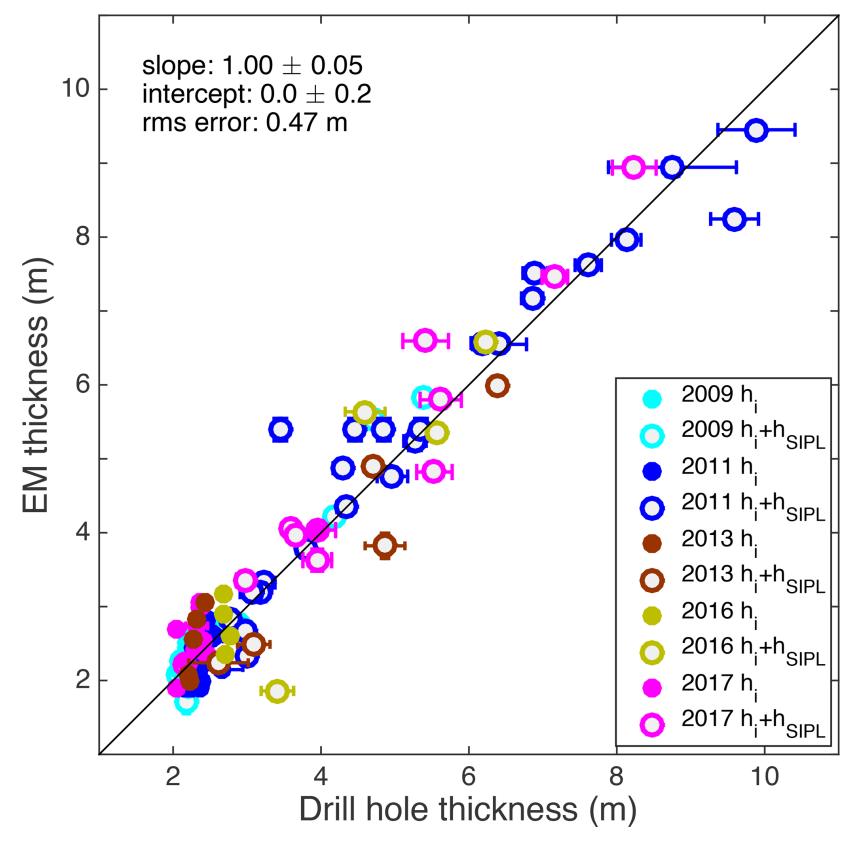

Figure 7. Scatter plot of EM derived vs. drill-hole consolidated ice thickness $\left(h_{\mathrm{i}}\right.$; filled symbols) and total thickness $\left(h_{\mathrm{i}}+h_{\text {sipl }}\right.$; open symbols), with symbol colour denoting year of measurement. Total thickness $\left(h_{\mathrm{i}}+h_{\text {silp }}\right)$ was calculated with $\alpha=0.4$ (best fit value $0.40 \pm 0.07, N=46$ ) for 2009,2011 , and 2017 and $\alpha=0.3$ for 2013 and 2016 (best fit value $0.30 \pm 0.15, N=9$ ); see Table 1 . Error bars show ice thickness variability at each calibration location (five drill holes) or within the approximate EM footprint (the latter are too small to be visible at the scale of the graph). The black line is $1: 1$. $N=9$ for $2009, N=26$ for $2011, N=5$ for 2013, $N=4$ for 2016, and $N=11$ for 2017; thus total $N=55$.

ments of consolidated ice thickness $h_{\mathrm{i}}, h_{\mathrm{a}, I}$ strongly underestimates total ice thickness $h_{\mathrm{i}}+h_{\text {sipl }}$. Therefore, according to Eq. (5b), the drill-hole measurements of SIPL thickness can be multiplied by a factor of $\alpha=0.4$ for best agreement with the in-phase AEM measurements. Note that this behaviour and value for $\alpha$ are also in good agreement with the model results and with the range of $\alpha$ values predicted by Fig. 5b.

The good agreement between $h_{\mathrm{a}, Q}$ and $h_{\mathrm{i}}$ from the drillhole data strongly supports our approach of using $h_{\mathrm{a}, Q}$ as the best estimate for $h_{\mathrm{i}}$ (Eq. 5a). This approach will be evaluated below (Fig. 7). In order to determine the best values for $\alpha$, we have fit the drill-hole-measured ice and SIPL thicknesses against $\left(h_{\mathrm{a}, I}-h_{\mathrm{a}, Q}\right)$ measured by the EM Bird at the same

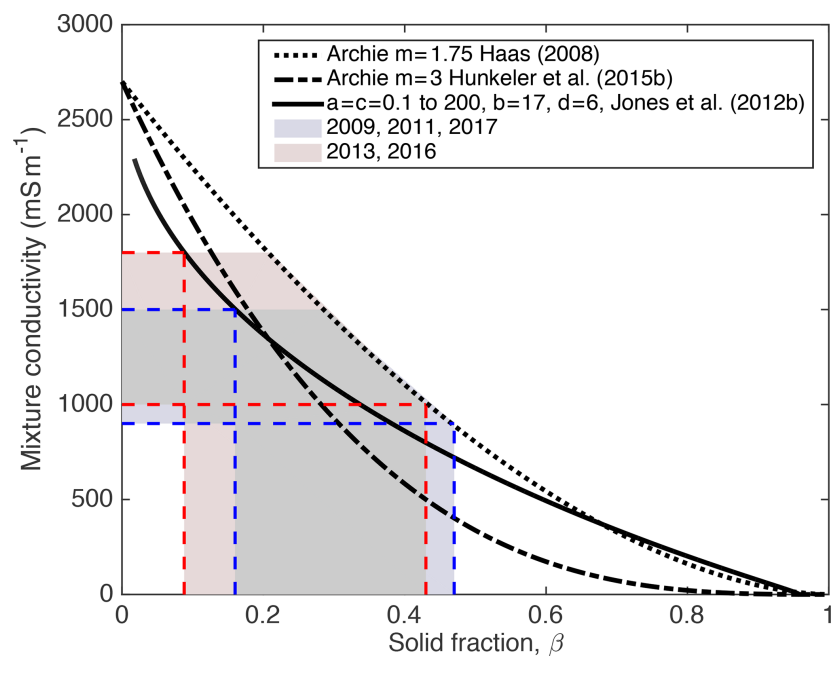

Figure 8. Conductivity vs. solid fraction for porous media according to theories by Archie (1942) with different cementation factors $m=1.75$ and 3 and Jones et al. (2012b; black curves). Coloured areas show the range of SIPL conductivities derived from comparison of drill-hole and EM SIPL thicknesses (Fig. 5b, Table 1) and resulting solid fractions according to the different theories.

sites. These values for $\alpha$ are summarized in Table 1. For firstyear, land-fast sea ice in 2009, 2011, and 2017, there are $N=$ 46 coincident measurements and they yield a best fit value of $\alpha=0.40 \pm 0.07$. A SIPL factor of $\alpha=0.4$ has been used for those years henceforth. Fewer drill-hole measurements were available in 2013 and $2016(N=9$ in total), resulting in a best fit of $\alpha=0.30 \pm 0.15$. We therefore use an SIPL scaling factor of $\alpha=0.3$ for 2013 and 2016 from here on.

With these $\alpha$ values we can then convert all in-phase and quadrature measurements into total consolidated ice plus SIPL thickness. Figure 7 shows a scatter plot of thicknesses thus derived vs. total drill-hole thicknesses. It demonstrates that EM-derived and drill-hole thicknesses agree very well, with a best fit line of slope $1.00 \pm 0.05$ and intercept $0.0 \pm 0.2$ (95\% confidence intervals) and root-mean-square error of $0.47 \mathrm{~m}$. Based on this and the discussion of Fig. 5 above we also estimate that the systematic error associated with the uncertainty in the simplified processing of the $h_{\mathrm{a}, Q}$ and $h_{\mathrm{a}, I}$ data and the choice of $\alpha$ yields a data reduction model uncertainty of $\pm 0.5 \mathrm{~m}$. 

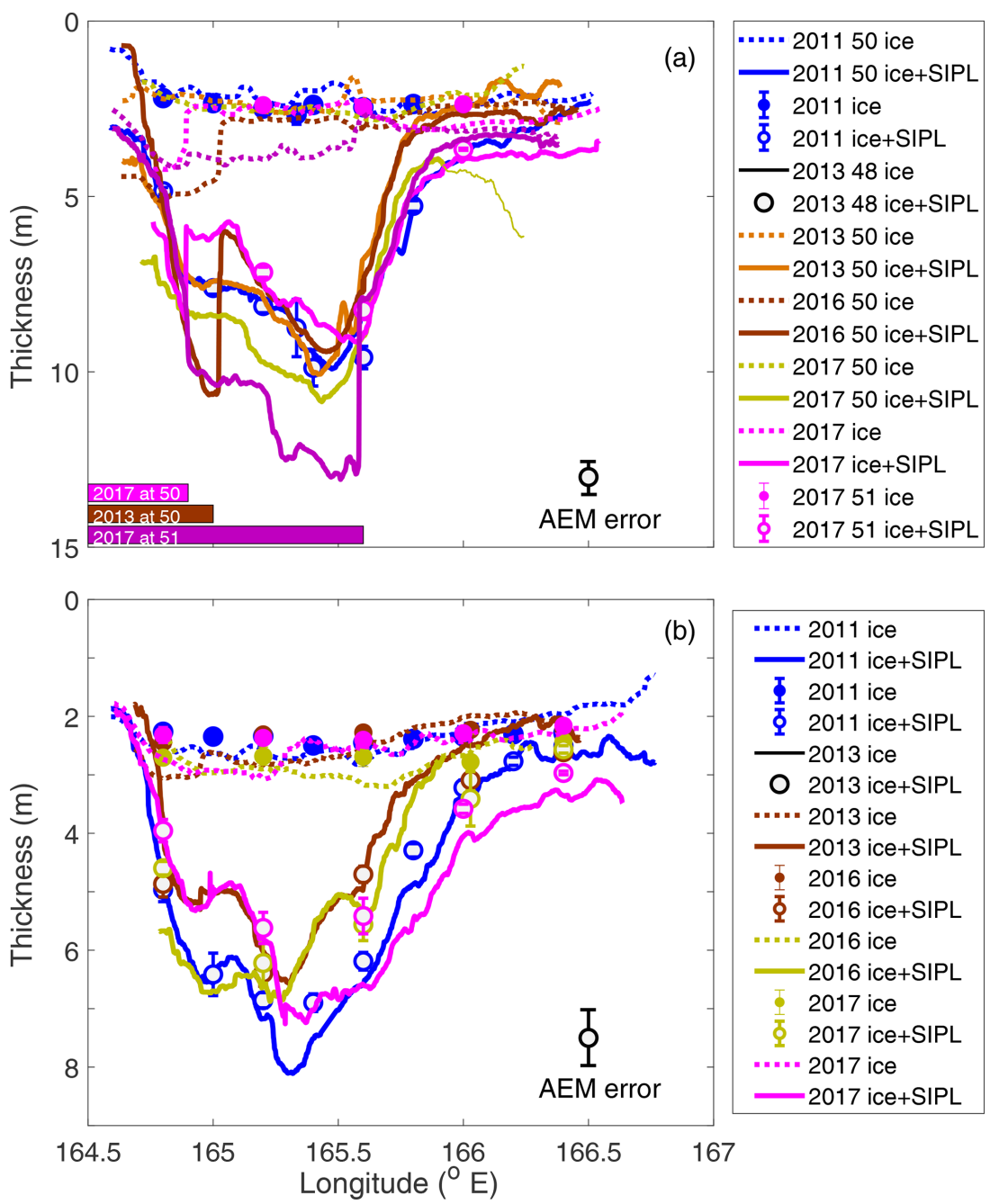

Figure 9. Interannual variability of AEM-derived and drill-hole-consolidated ice $h_{\mathrm{i}}$ (stippled lines and filled symbols) and total thickness $h_{\mathrm{i}}+h_{\text {sipl }}$ (solid lines and open symbols) along E-W transects at similar latitude (median filtered). (a) Transects at approximately $77^{\circ} 48^{\prime}$ to $77^{\circ} 51^{\prime} \mathrm{S}$ in November 2011, 2013, 2016, and 2017, approximately 3 to $5 \mathrm{~km}$ from the McMurdo Ice Shelf front. Horizontal bars indicate very thick MY ice present in the west along part of the profiles in 2013 and 2017. (b) Transect at approximately $77^{\circ} 46^{\prime} \mathrm{S}$ in November 2011 , 2013, 2016, and 2017, approximately $11 \mathrm{~km}$ from McMurdo Ice Shelf front. Note different $y$ axis scales, i.e. thicker SIPL farther south. The data reduction model uncertainty in AEM total thicknesses (snow + ice + SIPL) is shown.

\subsection{SIPL conductivity and solid fraction}

The SIPL scaling factors, $\alpha$, are highly sensitive to SIPL conductivity and thickness (Fig. 5b). However, with known $\alpha$ and SIPL thicknesses from the drill-hole calibrations in Sect. 3.2 (Table 1), we can narrow down the range of possible SIPL conductivities, in particular as the range of SIPL thicknesses only extends between 0 and $8 \mathrm{~m}$. The corresponding region of $\alpha$ values and SIPL thicknesses has been marked in Fig. 5b. It can be seen that most curves within this region have conductivities between 900 and $1800 \mathrm{mS} \mathrm{m}^{-1}$. The range of conductivities resulting from different $\alpha$ in the different years is listed in Table 1 .

In order to relate the conductivities to a solid fraction within the SIPL, we need a model of electrical conductivity,
Archie's law being the best known (Archie, 1942). Figure 8 shows the horizontal conductivity for Archie's law with tortuosity factor and saturation exponent set to 1 (e.g. Kovacs and Morey, 1986) and cementation factor $m=1.75$ (Haas et al., 1997) and $m=3$ (Hunkeler et al., 2015b), as the solid fraction is increased from 0 to 1 . For sea ice specifically, Jones et al. (2012a) have used a simple conductivity model (Jones et al., 2012b) to derive parameters for an ice/brine "unit cell". Each unit cell consists of a single, isolated, cubical brine pocket with sides of relative dimension $d$ (unitless) and three connected channels in perpendicular directions (two horizontal and one vertical direction), each with relative dimensions $c \times a \times b$ (also unitless). Jones et al. (2012b) found that the relative dimensions that fit the observed in situ DC 
horizontal and vertical resistivities depend not only on sea ice temperature but also on structure. In particular, for Antarctic incorporated platelet ice at $-5^{\circ} \mathrm{C}$, the shape of the inclusions has relative brine pocket dimensions $a \approx 1, b \approx 17, c \approx 0.6$, and $d \approx 6$ (see Jones et al., 2012a, for details). In addition, Jones et al. (2012b) have shown for Arctic first-year sea ice that there is a dramatic change in these parameters with temperature, with $a, c$, and $d$ becoming relatively larger, while $b$ drops. This behaviour would also be expected in incorporated platelet ice. We shall therefore assume that the shape of the inclusions in the SIPL is similar to that of incorporated platelet ice (as observed by Jones et al., 2012a) but that brine inclusion and void dimensions are very much larger because they are very close to the freezing point. Consequently, we calculate the relationship between solid fraction and conductivity from Jones et al. (2012b), by varying $a$ and $c$, while keeping $b$ and $d$ constant and hence changing the solid and liquid content of the SIPL (see Fig. 8).

From these curves, and the conductivities derived from the comparison of EM and drill-hole SIPL thicknesses (Fig. 5b, Table 1), we can estimate the corresponding solid fraction of the SIPL, with data in Fig. 8 grouped into two sets for the range of conductivities for $\alpha=0.4$ in blue (2009, 2011, 2017) and $\alpha=0.3$ in red $(2013,2016)$. Thus the airborne measurements imply that the range of solid fractions in the SIPL lies between 0.1 and 0.5 , but values are lower in 2013 and 2016 than in 2009, 2011, and 2017 (see Table 1 and Fig. 8). We shall discuss this interannual variability in Sect. 3.4.1.

\subsection{Spatial and interannual variability of the SIPL}

\subsubsection{Interannual variability and latitudinal differences}

Figure 9 shows the distribution of consolidated ice thickness $h_{\mathrm{i}}$ and total ice thickness $h_{\mathrm{i}}+h_{\text {sipl }}$ along two E-W transects in 2011, 2013, 2016, and 2017, derived from the AEM surveys and drill-hole data. The transects are 3 to $5 \mathrm{~km}$ (Fig. 9a) and $11 \mathrm{~km}$ north of the ice shelf front Fig. (9b). In 2013 and 2017 there was some multiyear ice in southwestern McMurdo Sound (see Fig. 1d and f), and at these locations both consolidated ice and the SIPL show abrupt increases in thickness.

The figure shows a generally thicker SIPL along the southern transect, in agreement with the notion of a thick SIPL that emerges from under the ice shelf and thins towards the north, with increasing distance from the ice shelf. Over the firstyear ice, on both transects $h_{\mathrm{i}}$ varies by less than $0.75 \mathrm{~m}$ from year to year, while variations of up to $2 \mathrm{~m}$ are seen in SIPL thickness $h_{\text {sipl. }}$. While there is interannual variability in the thickness of the SIPL, the shape of the thickness distribution is remarkably consistent from year to year.

\subsection{Evidence of persistent, recurring SIPL pattern}

Close inspection of the thickness data in all years and at all latitudes reveals the presence of persistent, recurring local maxima or clear shoulders in the thickness profiles. Typical examples that were identified are illustrated by A and B in the repeated profiles along transect $77^{\circ} 46^{\prime} \mathrm{S}$ in $2011,2013,2016$, and 2017 in Fig. 10a. Figure 10b shows that these maxima are also present in a series of profiles at increasing latitude or decreasing distance from the front of the McMurdo Ice Shelf. While Fig. 10a also shows the typical interannual variability of up to $2 \mathrm{~m}$ in SIPL thickness already seen in Fig. 9, Fig. 10b nicely demonstrates the decreasing SIPL thickness with increasing distance from the ice shelf already indicated by the differences between Fig. 9a and $b$.

For comparison, Fig. 10b also includes data from AEM and laser altimeter surveys of the McMurdo Ice Shelf near its front at $77^{\circ} 55^{\prime} \mathrm{S}$ (see ice shelf locations in Fig. 11) in November 2009 and 2017. It shows the ice freeboard in 2009 from Rack et al. (2013) and an uncalibrated measure of the SIPL thickness beneath the ice shelf. The latter was derived from the difference between in-phase and quadrature apparent thicknesses, $h_{\mathrm{a}, I}-h_{\mathrm{a}, Q}$, but no scaling was applied. Note that the ratio between $h_{\mathrm{a}, Q}$ and $h_{\mathrm{i}}$ and scaling factor $\alpha$ (Eqs. 5) under the 20 to more than $50 \mathrm{~m}$ thick ice shelf could be quite different than under $2 \mathrm{~m}$ thick sea ice and that no calibration measurements were available.

Figure $10 \mathrm{~b}$ shows that the locations of the local maxima in SIPL thickness under the ice shelf in 2017 coincide very well with the ice shelf freeboard of Rack et al. (2013) in 2009. This could be due to preferential accretion of marine ice in those locations or due to the increased buoyancy from the SIPL under the ice shelf (Rack et al., 2013). Even more importantly, the locations of the SIPL thickness maxima under the ice shelf coincide approximately with the locations of SIPL thickness maxima under the fast ice to the north, providing evidence that the structure of the SIPL under the fast ice is directly linked to the geometry of the ISW outflow from under the ice shelf.

The local maxima A and B illustrated in Fig. 10 can be visually identified in some transects from all years 2009, 2011, 2013, 2016, and 2017 and their positions are shown in regional context on the map in Fig. 11. The peaks clearly originate under the ice shelf and propagate beneath the sea ice, carried northward by the ISW plume. The thickest peak A appears to be carried westward, as is also visible in Fig. 10. The westward displacement of this peak may be supported by the Coriolis force acting on the northward-flowing ISW (Robinson et al., 2014), as suggested by the modelling of Cheng et al. (2019) and Holland and Feltham (2005). Peak B is farther west and appears to originate from under the ice shelf near the Koettlitz glacier. Its course is more northerly as it may be constrained by the $200 \mathrm{~m}$ isobath. While the ice shelf thickness measurements near the front are uncalibrated, they 


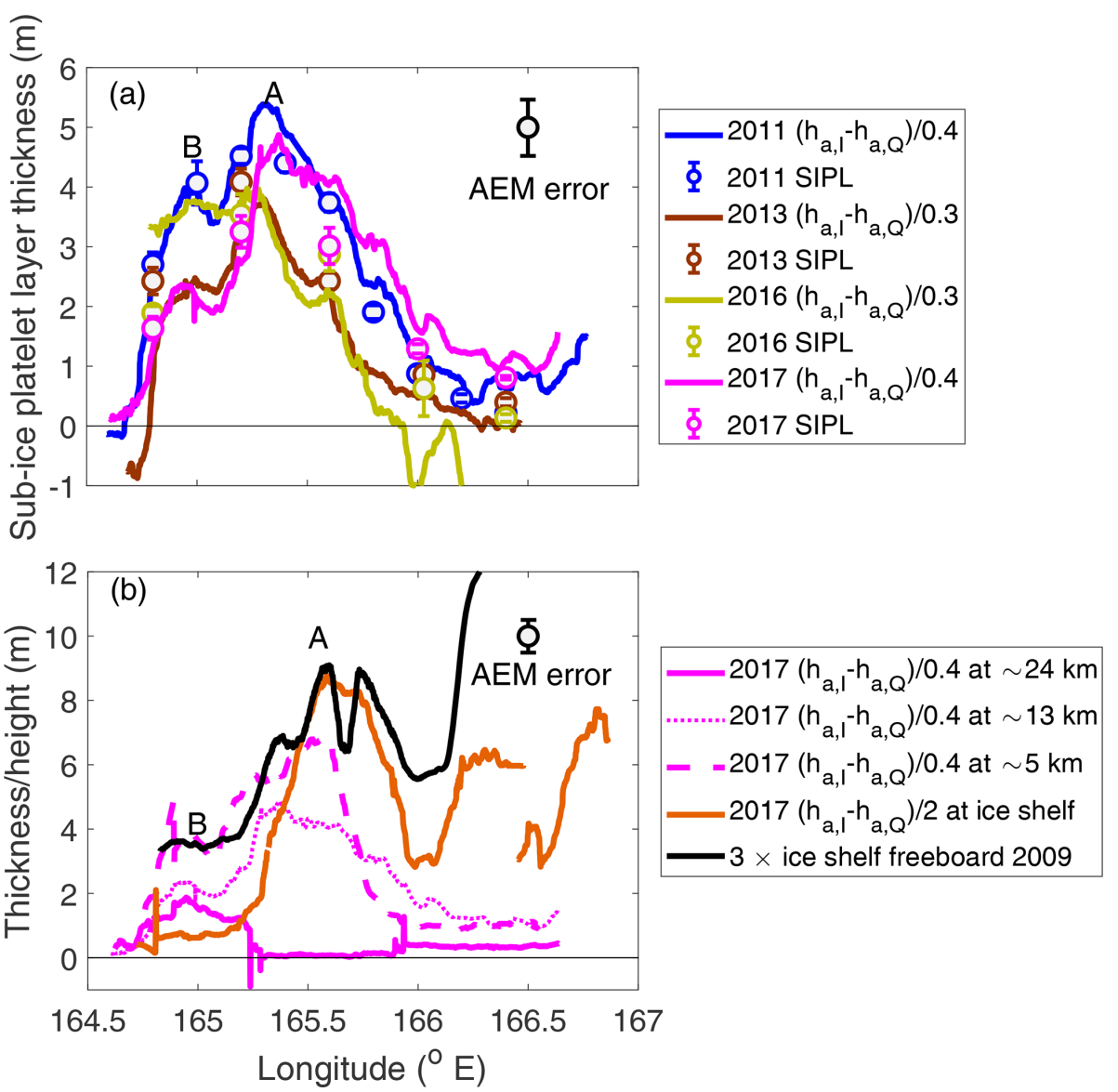

Figure 10. (a) SIPL thickness along $77^{\circ} 46^{\prime} \mathrm{S}$ in 2011, 2013, 2016, and 2017, approximately $11 \mathrm{~km}$ from McMurdo Ice Shelf front. Recurring local maxima or shoulders in thickness are identified at A and B. (b) SIPL thickness profiles in November 2017 at different distances from McMurdo Ice Shelf front (pink lines), at approximately $24 \mathrm{~km}$ (solid), $13 \mathrm{~km}$ (dotted), and $5 \mathrm{~km}$ (dashed). The figure also shows uncalibrated, scaled SIPL thickness beneath the ice shelf in 2017 (brown) and scaled ice shelf freeboard in 2009 (black; from Rack et al., 2013), at 77 55 5. The ice shelf data are smoothed by a moving-average filter of window size 50. Local thickness maxima are identified at A and B. The data reduction model uncertainty in AEM total thicknesses (snow + ice + SIPL) is shown.

are generally in agreement with thicknesses from 1960-1984 (McCrae, 1984) and from 2015 (Campbell et al., 2017).

Finally, Fig. 12a shows the thickness of peaks A and B from Fig. 11 vs. latitude. Thicknesses were averaged over a width $0.1^{\circ}$ of longitude centred on the peak location to be statistically more representative. Although quite noisy, the figure shows that peak $\mathrm{A}$ is generally larger than peak $\mathrm{B}$, and that both are decreasing with distance from the ice shelf front. Peak A decreases from a maximum SIPL thickness of $8 \mathrm{~m}$ approximately $3 \mathrm{~km}$ from the front to less than $3 \mathrm{~m}$ at $24 \mathrm{~km}$, i.e. over a distance of $21 \mathrm{~km}$. The relatively large scatter of up to $2 \mathrm{~m}$ at single locations is due to the described interannual variability and retrieval uncertainty. At the northernmost transect $24 \mathrm{~km}$ from the ice shelf $\left(77^{\circ} 40^{\prime} \mathrm{S}\right)$ only one peak was identifiable. It is quite possible that the converging paths of peaks A and B have merged at that latitude.

In contrast, Fig. 12b shows integrated SIPL thicknesses across the complete individual east-west transects. The inte- gral was calculated for cross sections with SIPL thicknesses of at least $1 \mathrm{~m}$. A few thickness surveys had to be ended before SIPL thickness decreased below $1 \mathrm{~m}$ in the west, near the coast. In these cases data were simply extrapolated following the generally steeply decreasing thickness gradients found in the west (e.g. Fig. 10a). These integral thicknesses are less influenced by the peak thicknesses but more representative of the overall volume of SIPL at the different distances from the ice shelf. However, the same general behaviour as with peak thicknesses in Fig. 12a can be seen, with all peaks decreasing in thickness with distance from the ice shelf, from south to north. The figure also confirms that SIPL thicknesses and therefore volumes were larger in 2011 and 2017 than in 2013 and 2016. These results are in general agreement with SIPL volumes derived from ground-based EM surveys by Brett et al. (2020) also shown in Fig. 12b. Note that absolute values are difficult to compare because Brett et al. (2020) de- 


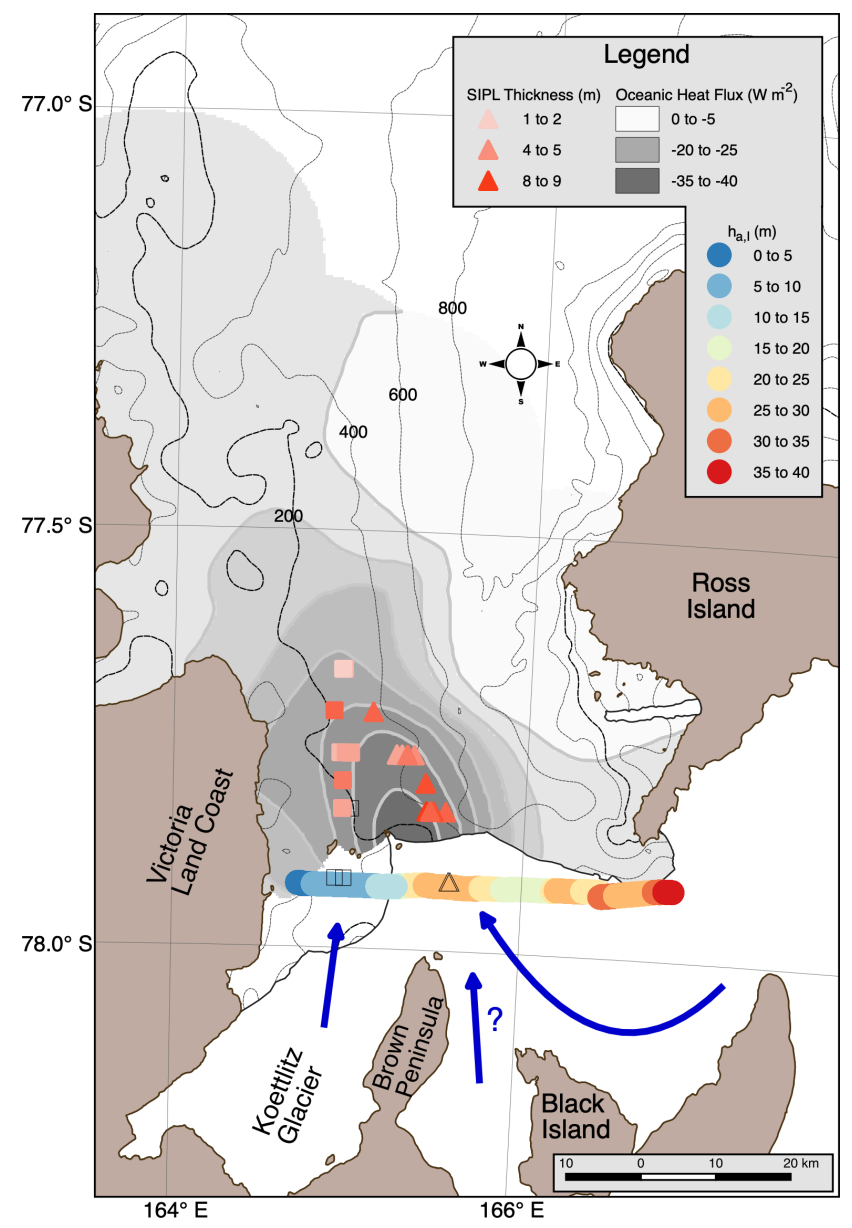

Figure 11. Bathymetric map of McMurdo Sound showing the location of local maxima in SIPL thickness, with peak A as triangles and B as squares for all years 2009, 2011, 2013, 2016, and 2017. The magnitudes of the local maxima are coloured proportionally to the thickness of the peak, with darker orange for thicker average SIPL. Open symbols denote peaks whose absolute thicknesses were uncertain. Coloured horizontal line shows ice shelf $h_{\mathrm{a}, I}$ profile flown in 2017 with locations of corresponding A and B peaks identified. Contours in grey are proportional to negative ocean heat flux from Langhorne et al. (2015). Blue arrows indicate possible paths of surface ISW (based on Robinson et al., 2014).

rived their average results from data that were spatially gridded across the central McMurdo Sound.

\section{Discussion}

In this study we have presented a new, simple method to map the distribution and thickness of a sub-ice platelet layer (SIPL) by means of airborne EM surveying. The accuracy of the method was assessed with theoretical considerations and by means of comparisons with drill-hole data. Regression of EM results with drill-hole data showed very low bias with a slope of 1 and intercept of $0 \mathrm{~m}$, but a root mean square error
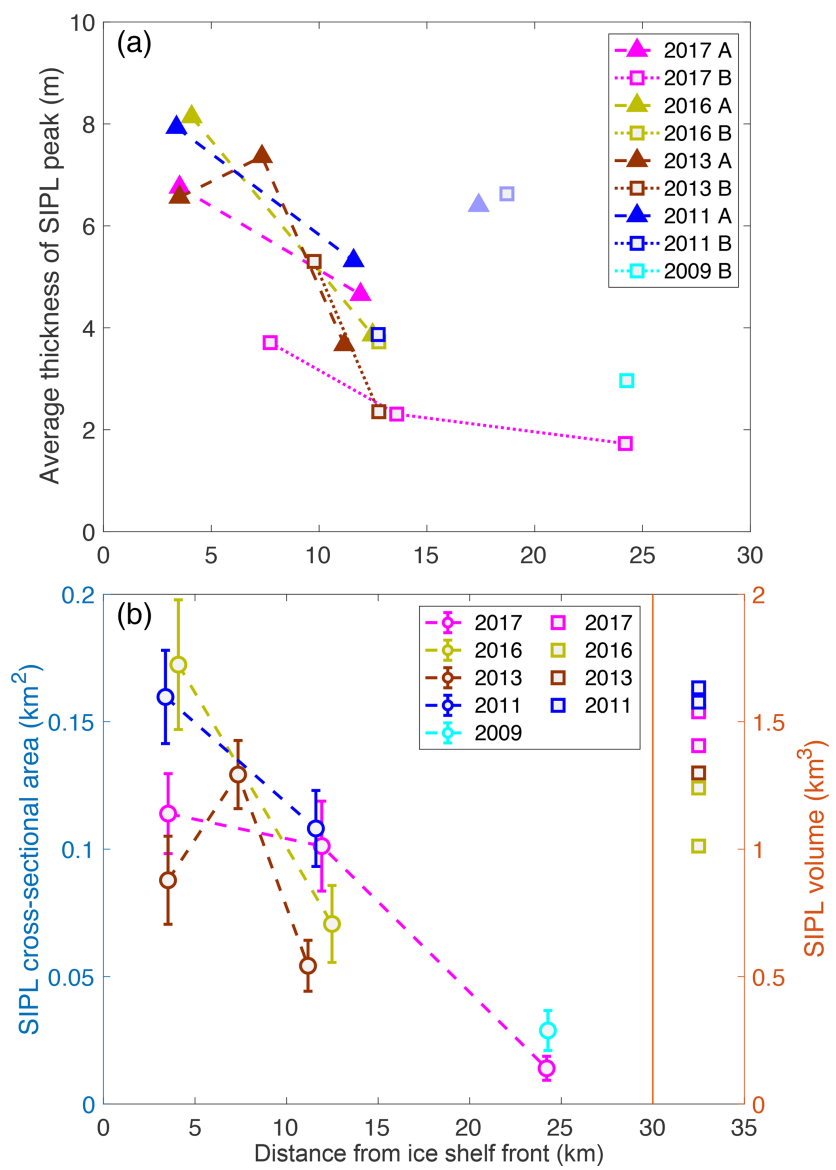

Figure 12. (a) SIPL thickness of peaks A and B (averaged over $0.1^{\circ}$ of longitude) vs. distance from ice shelf front for all years 2009, 2011, 2013, 2016, and 2017 (see Fig. 11). (b) East-west crosssectional area through the SIPL region (defined as greater than $1 \mathrm{~m}$ thickness). Simultaneous SIPL volumes over a $675 \mathrm{~km}^{2}$ area in the central McMurdo Sound from Brett et al. (2020) are shown on the right (squares). Error bars assume a $\pm 0.5 \mathrm{~m}$ data reduction model uncertainty in EM SIPL measurements (Sect. 3.2).

of $0.47 \mathrm{~m}$. This uncertainty is partially due to the EM measurement noise on the order of $10 \mathrm{ppm}$ in $I$ and $Q$, whose effect on retrieved ice thicknesses increases with increasing thickness and decreasing $I$ and $Q$ signals, due to the negative exponential EM response to increasing ice thickness.

In a few instances, we also observed that the retrieved SIPL thicknesses were actually negative but still within the derived rms errors (e.g. Fig. 10a). Negative values arise when the in-phase-derived apparent total thickness is smaller than the quadrature-derived apparent consolidated ice thickness (Eq. 5c), which can happen when the SIPL is very thin or absent. The quadrature signals are not only much weaker than the in-phase signals (Fig. 3), but they are also subject to stronger electronic instrument drift. This makes the detection of SIPL layers thinner than $0.5 \mathrm{~m}$ very challenging.

In addition to uncertainties due to instrument effects, variable SIPL conductivities contribute to variations in the EM 
response even with constant SIPL thicknesses. In fact our inversions suggest quite a wide range of SIPL conductivities between 900 and $1800 \mathrm{mS} \mathrm{m}^{-1}$, which is larger than the relatively narrow estimates of 900 to $1400 \mathrm{mS} \mathrm{m}^{-1}$ by Hunkeler et al. (2015a, b). This led us to distinguish between different SIPL conductivities of 900 to $1500 \mathrm{mS} \mathrm{m}^{-1}$ in 2009 , 2011, and 2017 and 1000 to $1800 \mathrm{mS} \mathrm{m}^{-1}$ in 2013 and 2016. These interannual differences also led to different SIPL scaling factors $\alpha$ in the different years, $\alpha=0.4$ in 2009, 2011, and 2017 and $\alpha=0.3$ in 2013 and 2016, in agreement with reduced EM sensitivity for higher SIPL conductivities. The separation between these years was only possible due to the availability of drill-hole calibration data. In the absence of drill-hole data the uncertainties would be larger than in this study and can best be inferred from Fig. 5, which showed the range of possible variability of the consolidated ice thickness retrieval $h_{\mathrm{a}, Q} / h_{\mathrm{i}}$ and of the SIPL scaling factor $\alpha$. Consequently, there is a data reduction model uncertainty of $0.5 \mathrm{~m}$ that accounts for these simplifying assumptions in the use and choice of $\alpha$.

In 2013 and 2016 we not only found higher SIPL conductivities than in 2009, 2011, and 2017, but those were also the 2 years with a thinner SIPL (see Fig. 12 b). It is intriguing to consider whether there is a relationship between thinner SIPL and larger SIPL conductivity, i.e. negative correlation between SIPL thickness and conductivity. Similar behaviour was observed by Hunkeler et al. (2015b) and Hoppmann et al. (2015). They observed negatively correlated SIPL thickness and conductivity with variable SIPL thickness along their profiles surveyed within a few days, while our observations represent spatially averaged, annual conditions obtained over a period of several years. However, the general behaviour could potentially be explained by the age of the SIPL or the intensity of SIPL formation in a certain location or year, where more rapid or more massive SIPL formation is caused by more intensive inflow of supercooled ISW under the fast ice, or by longer accumulation times. Both processes may support more rapid or extensive consolidation of the SIPL interstitial pore space, which increases solid fraction and decreases conductivity, thus causing the observed behaviour.

Our validation data are limited to drill-hole measurements from first-year fast ice that is typically $2 \mathrm{~m}$ thick at the end of the winter. Therefore, most of our model results were also limited to $2 \mathrm{~m}$ thick consolidated ice. However, Fig. 5 also includes results for 4 and $6 \mathrm{~m}$ thick consolidated ice (dashed curves). From the behaviour of those model curves it can be inferred that with thicker consolidated ice the ratio of $h_{\mathrm{a}, Q} / h_{\mathrm{i}}$ decreases, which suggests that, in the presence of a typical SIPL, thicker consolidated ice can be retrieved more accurately than thinner ice from the quadrature measurements. Figure 5 also shows that the scaling factor $\alpha$ is hardly affected by consolidated ice thickness at all, i.e. the accuracy of retrieved SIPL thicknesses is independent of ice thickness. The thickness profiles in Fig. 9a include surveys of multi- year fast ice in 2013 and 2017, which are visible by large steps towards thicker ice in the west. These are indications that the measurements are indeed quite sensitive to thicker consolidated ice and SIPL as well. We only attempted very few drill-hole measurements of the thick consolidated ice and thick SIPL, as they are very challenging and their accuracy is poor. Therefore we did not include them in our analysis here.

However, thick consolidated ice and a thick SIPL pose other challenges that are related to the decreasing sensitivity of EM measurements with increasing height above the water or conductive SIPL. Despite the better behaviour of $h_{\mathrm{a}, Q} / h_{\mathrm{i}}$ discussed above with regard to Fig. 5 , thicker consolidated ice results in weaker in-phase and quadrature signals which eventually approach the EM noise level and are then insensitive to consolidated ice thickness changes (not shown here; see Haas et al., 2009). However, these limitations only apply to consolidated ice several tens of metres thick (e.g. Rack et al., 2013). More importantly, increasing SIPL thicknesses also lead to reduced sensitivities, particularly of the in-phase signals as was discussed above with regard to results shown in Fig. 3. That figure shows that for typical SIPL conductivities of $900 \mathrm{mS} \mathrm{m}^{-1}$ and more, the in-phase signal remains approximately constant for SIPL thickness of $6 \mathrm{~m}$ and more. This is due to the limited EM field depth penetration into conductive layers, which make the method insensitive to changes below the level of penetration. Therefore it is likely that the good results shown in Fig. 7 benefited from the fact that most drill-hole SIPL thicknesses in the study region were not larger than $6 \mathrm{~m}$ (total thickness of $8 \mathrm{~m}$ ). In fact, Fig. 7 shows that the uncertainties of the thickest SIPL measurements which also have the largest drill-hole errors are considerably larger than those of smaller total thicknesses.

Despite the uncertainties discussed above, our results are in close agreement with the results of Brett et al. (2020), who used ground-based EM surveys to find that SIPL thicknesses in McMurdo Sound were less in 2013 and 2016 than in 2011 and 2017. As Brett et al. (2020) demonstrate, thicker SIPLs occur in years with the occurrence of more frequent strong southerly winds and hence higher polynya activity.

We provide direct evidence that the ISW plume of McMurdo Sound flows out from beneath the McMurdo Ice Shelf. Our results show consistently that the SIPL extent in the west displays relatively little interannual variability, while variability near its eastern margin is quite large (Figs. 9 and 10). In addition, east-west SIPL thickness gradients are greater in the west than in the east. As the SIPL structure and thickness are closely related to the properties of the outflowing ISW to the south, we agree with Robinson et al. (2014) that the ISW outflow from the McMurdo Ice Shelf in the west is strongly controlled by bathymetry and the fact that the western margin is close to the coast and constrained by shallow water (Jendersie et al., 2018). The location of the western peak of SIPL thickness at water depths of around $200 \mathrm{~m}$ (Fig. 11) suggests that the currents driving the ISW plume are constrained by bathymetry there (Robinson et al., 
2014). In contrast, in the east the ISW structure is dependent on the interplay with the warmer and more saline water inflowing from the north on the eastern side of McMurdo Sound (Leonard et al., 2006; Mahoney et al., 2011; Leonard et al., 2011; Robinson et al., 2014). The interplay controls both the extent and thickness of the SIPL in eastern McMurdo Sound. The source of the ISW outflow is the RossMcMurdo ice shelf (Robinson et al., 2014; Jendersie et al., 2018), and there are a number of possible explanations for the two local peaks observed in the SIPL thickness. The first is that the two streams arise from different sources: Robinson et al. (2014) suggested that one local maxima (peak B) may be from the Koettlitz Glacier which has retreated for over 100 years (Gow and Govoni, 1994). The larger maximum, peak A, likely originates from the confluence of the McMurdo and Ross ice shelves (Robinson et al., 2014) as indicated by the arrow north of Black Island in Fig. 11. Alternatively, marine ice has been found in the southern McMurdo Ice Shelf (Koch et al., 2015; Grima et al., 2019) and a possible additional source may emerge from the channel between Black Island and the Brown Peninsula (see Figs. 1a and 11). Once it emerges from under the ice shelf and spreads out under the fast ice, this stream moves westward under the influence of the Coriolis force (Robinson et al., 2014) as modelled by Cheng et al. (2019). Alternatively, it may be that there is one ISW outflow that is split by sea floor and ice shelf morphology and islands close to the ice shelf front. More concurrent oceanographic and EM surveys are required to further study this interplay within the coastal current that flows northward up the coast of Victoria Land.

\section{Conclusions}

We have presented results from five AEM ice thickness surveys of the landfast ice in McMurdo Sound in November of 2009, 2011, 2013, 2016, and 2017 with the aim of describing the spatial and interannual variability of the sub-ice platelet layer (SIPL) known to exist below the fast ice. We have presented a simple method to obtain approximate SIPL thickness and conductivity information from the in-phase and quadrature components of single-frequency AEM data, which were calibrated and validated with drill-hole measurements. Forward EM modelling demonstrated the varying sensitivity and accuracy of the method over ice with variable thickness and underlain with a SIPL with variable thickness and conductivity. Results are in good agreement with previous knowledge of the SIPL distribution, thickness, and conductivity and solid fraction in McMurdo Sound. However, the extensive, continuous data with high spatial resolution that are possible with airborne surveys provided new insights into the small-scale spatial variability of SIPL thickness and in particular provide novel evidence for the presence of at least two elongated regions of thicker SIPL that may bear information about the structure of the ice shelf water (ISW) plume. We were able to show that the spatial occurrence of those thicker SIPL regions closely corresponds to thickness and SIPL occurrence under the ice shelf, thus linking processes under the ice shelf with the structure of the SIPL under the landfast ice.

The association of the SIPL with ISW and its link to melting and circulation processes under ice shelves makes our approach particularly attractive for exploratory mapping of the vast, remote regions of fast ice fringing the circum-Antarctic ice shelves. We could easily discover the occurrence and thickness of a SIPL in these unstudied regions. Variations in the thickness of the SIPL are indicators of intensive, nearsurface ISW outflow in response to ice shelf bottom melt. Such mapping could therefore identify potential "hotspots" of present basal ice shelf melt and could provide important advance information for subsequent future more comprehensive ice-shelf and ocean studies. The network of circumpolar coastal Antarctic research stations and their airfields makes it entirely feasible to carry out such a survey with Basler aircraft that are used by many national Antarctic research programs.

Data availability. All data will be made available at the World Data Center PANGAEA https://www.pangaea.de/?q=Haas\%2C+ Christian\&f.pubyear\%5B\%5D=2021 (last access: February 2021, Haas et al., 2021).

Author contributions. CH, PJL, and WR designed the field experiments, analysed the data, developed the retrieval algorithm, and secured the required funds. All authors contributed to field data acquisition and writing of the manuscript.

Competing interests. The authors declare that they have no conflict of interest.

Acknowledgements. We are most grateful for the logistics support and aircraft funds provided by Antarctica NZ and the welcoming staff at Scott Base. We particularly thank Johno Leitch and his team for excellent ground support for the Basler BT67 airplane campaigns in 2016 and 2017. The success of this project would not have been possible without the dedication of Helicopter NZ pilot Rob McPhail, Southern Lakes Helicopters pilot Hannibal Hayes, the Kenn Borek Air BT67 captains Gary Murtsell and Jamie Chisholm, and their respective air and ground crews. Field logistics and air time were funded by Targeted observations and process-informed modeling of Antarctic sea ice through the Deep South National Science Challenge + K053 K063 (2009, 2013, 2011). Christian Haas acknowledges infrastructure and operation funding by Alberta Ingenuity Scholarship grant AITFschoptg_200700043_Haas, Tier 1 Canada Research Chair grant no. 950-228139, and NSERC Discovery grant no. 356589 . Finally we are grateful for reviewer comments by Blake R. Weissling and Andy Mahoney, as well as edi- 
tor comments from Ted Maksym, which considerably improved the manuscript.

Financial support. The article processing charges for this openaccess publication were covered by the University of Bremen.

Review statement. This paper was edited by Ted Maksym and reviewed by Andrew Mahoney and Blake P. Weissling.

\section{References}

Archie, G. E.: The electrical resistivity log as an aid in determining some reservoir characteristics, Trans. Am. Inst. Min. Metall. Petr. Eng., 146, 54-62, 1942.

Barry, J. P.: Hydrographic patterns in McMurdo Sound, Antarctica and their relationship to local benthic communities, Polar Biol., 8, 377-391, https://doi.org/10.1007/BF00442029, 1988.

Brett, G. M., Irvin, A., Rack, W., Haas, C., Langhorne, P. J., and Leonard, G. H.: Variability in the distribution of fast ice and the sub-ice platelet layer near McMurdo Ice Shelf, J. Geophys. Res.-Oceans, 125, e2019JC015678, https://doi.org/10.1029/2019JC015678, 2020.

Brunt, K. M., Sergienko, O., and MacAyeal, D. R.: Observations of unusual fast-ice conditions in the southwest Ross Sea, Antarctica: preliminary analysis of iceberg and storminess effects, Ann. Glaciol., 44, 183-118, 2006.

Campbell, S., Courville, Z., Sinclair, S., and Wilner, J.: Brine, englacial structure and basal properties near the terminus of McMurdo Ice Shelf, Antarctica, Ann. Glaciol., 58, 1-11, https://doi.org/10.1017/aog.2017.26, 2017.

Cheng, C., Jenkins, A., Holland, P. R., Wang, Z., Liu, C., and Xia, R.: Responses of sub-ice platelet layer thickening rate and frazilice concentration to variations in ice-shelf water supercooling in McMurdo Sound, Antarctica, The Cryosphere, 13, 265-280, https://doi.org/10.5194/tc-13-265-2019, 2019.

Dempsey, D. E., Langhorne, P. J., Robinson, N. J., Williams, M. J. M., Haskell, T. G., and Frew, R. D.: Observation and modeling of platelet ice fabric in McMurdo Sound, Antarctica, J. Geophys. Res., 115, C01007, https://doi.org/10.1029/2008JC005264, 2010.

Gough, A. J., Mahoney, A. R., Langhorne, P. J., Williams, M. J. M., Robinson, N. J., and Haskell, T. G.: Signatures of supercooling: McMurdo Sound platelet ice, J. Glaciol., 58, 38-50, https://doi.org/10.3189/2012JoG10J218, 2012.

Gow, A. J. and Govoni, J. W.: An 80 year record of retreat of the Koettlitz Ice Tongue, McMurdo Sound, Antarctica, Ann. Glaciol., 20, 237-241, 1994.

Gow, A. J., Ackley, S. F., Govoni, J. W., and Weeks, W. F.: Physical and Structural Properties of Land-Fast Sea Ice in McMurdo Sound, Antarctica, in: Antarctic Sea Ice: Physical Processes, Interactions and Variability, edited by: Jeffries, M. O., American Geophysical Union, Washington, D.C., https://doi.org/10.1029/AR074p0355, 1998.

Grima, C., Koch, I., Greenbaum, J. S., Soderlund, K. M., Blankenship, D. D., Young, D. A., Schroeder, D. M., and Fitzsimons, S.: Surface and basal boundary conditions at the Southern Mc-
Murdo and Ross Ice Shelves, Antarctica, J. Glaciol., 65, 675-688 https://doi.org/10.1017/jog.2019.44, 2019.

Guptasarma, D. and Singh, B.: New digital linear filters for Hankel J0 and J1 transforms, Geophys. Prospect., 45, 745-762, https://doi.org/10.1046/j.1365-2478.1997.500292.x, 1997.

Haas, C.: Airborne electromagnetic sea ice thickness sounding in shallow, brackish water environments of the Caspian and Baltic Seas, Proceedings of OMAE2006 25th International Conference on Offshore Mechanics and Arctic Engineering, 4-9 June 2006, Hamburg, Germany, 6 pp., 2006.

Haas, C., P. J. Langhorne, W. Rack, G. H. Leonard, G. M. Brett, D. Price, J. F. Beckers, and A. J. Gough: Subice platelet layer thickness in McMurdo Sound, Antarctica, 2009-2017, Pangaea, https://www.pangaea.de/?q=Haas\% 2C+Christian\&f.pubyear $\% 5 B \% 5 D=2021$, last access: February 2021.

Haas, C. and Druckenmiller, M.: Ice thickness and roughness measurements, in: Sea-ice handbook, edited by: Eicken, H., University of Alaska Press, Fairbanks, Alaska, 2009.

Haas, C., Gerland, S., Eicken, H., Miller, H.: Comparison of sea-ice thickness measurements under summer and winter conditions in the Arctic using a small electromagnetic induction device, Geophysics, 62, 749-757, 1997.

Haas, C., Lobach, J., Hendricks, S., Rabenstein, L., and Pfaffling, A.: Helicopter-borne measurements of sea ice thickness, using a small and lightweight, digital EM system, J. Appl. Geophys., 67, 234-241, https://doi.org/10.1016/j.jappgeo.2008.05.005, 2009.

Haas, C., Hendricks, S., Eicken, H., and Herber, A.: Synoptic airborne thickness surveys reveal state of Arctic sea ice cover, Geophys. Res. Lett., 37, L09501, https://doi.org/10.1029/2010GL042652, 2010.

Holland, P. R. and Feltham, D. L.: Frazil dynamics and precipitation in a water column with depth-dependent supercooling, J. Fluid Mech., 530, 101-124, 2005.

Hoppmann, M., Nicolaus, M., Hunkeler, P. A., Heil, P., Behrens, L. K., König-Langlo, G., and Gerdes, R.: Seasonal evolution of an ice-shelf influenced fast-ice regime, derived from an autonomous thermistor chain, J. Geophys. Res.-Oceans, 120, 1703-1724, https://doi.org/10.1002/2014JC010327, 2015.

Hoppmann, M., Richter, M., Smith, I., Jendersie, S., Langhorne, P., Thomas, D., and Dieckmann, G.: Platelet ice, the Southern Ocean's hidden ice: A review, Ann. Glaciol., 1-28, https://doi.org/10.1017/aog.2020.54, 2020.

Hughes, K., Langhorne, P., Leonard, G., and Stevens, C.: Extension of an Ice Shelf Water plume model beneath sea ice with application in McMurdo Sound, Antarctica, J. Geophys. Res.-Oceans, 119, 8662-8687, 2014.

Hunkeler, P. A., Hendricks, S., Hoppmann, M., Paul, S., and Gerdes, R.: Towards an estimation of sub-sea-ice platelet-layer volume with multi-frequency electromagnetic induction sounding, Ann. Glaciol., 56, 137-146, https://doi.org/10.3189/2015AoG69A705, 2015a.

Hunkeler, P. A., Hoppmann, M., Hendricks, S., Kalscheuer, T., and Gerdes, R.: A glimpse beneath Antarctic sea ice: Platelet layer volume from multifrequency electromagnetic induction sounding, Geophys. Res. Lett., 43, 222-231, https://doi.org/10.1002/2015GL065074, 2015b. 
Irvin, A.: Towards multi-channel inversion of electromagnetic sea ice surveys, doctoral thesis, York University, Toronto, Canada, available at: http://hdl.handle.net/10315/35925 (last access: 13 January 2021), 2018.

Irvin, A.: One Dimensional Frequency domain Electromagnetic Model (ODFEM), PANGAEA, https://doi.org/10.1594/PANGAEA.897352, 2019.

Jendersie, S., Williams, M., Langhorne, P. J., and Robertson, R.: The density-driven winter intensi?cation of the Ross Sea circulation, J. Geophys. Res.-Oceans, 123, 7702-7724, https://doi.org/10.1029/2018JC013965, 2018.

Jones, K. A., Gough, A. J., Ingham, M., Mahoney, A. M., Langhorne, P. J., and Haskell, T. G.: Detection of differences in sea ice crystal structure using cross-borehole DC resistivity tomography. Cold Reg. Sci. Technol., 78, 40-45, https://doi.org/10.1016/j.coldregions.2012.01.013, 2012a.

Jones, K. A., Ingham, M., and Eicken, H.: Modelling the anisotropic brine microstructure in first-year sea ice, J. Geophys. Res., 117, C02005, https://doi.org/10.1029/2011JC007607, 2012 b.

Kim, S., Saenz, B., Scanniello, J., Daly, K., and Ainley, D.: Local climatology of fast ice in McMurdo Sound, Antarctica, Antarct. Sci., 30, 125-142, 2018.

Koch, I., Fitzsimons, S., Samyn, D., and Tison, J- L.: Marine ice recycling at the southern McMurdo Ice Shelf, Antarctica, J. Glaciol., 61, 689-701, https://doi.org/10.3189/2015JoG14J095, 2015.

Kovacs, A. and Morey, R. M.: Electromagnetic measurements of multi-year sea ice using impulse radar, Cold Reg. Sci. Technol., 12, 67-93, https://doi.org/10.1016/0165-232X(86)90021-2, 1986.

Kovacs, A. and Morey, R. M.: Sounding sea ice thickness using a portable electromagnetic induction instrument, Geophysics, 56, 1992-1998, 1991.

Kovacs, A., Holladay, J. S., and Bergeron, C. J.: The footprint/altitude ratio for helicopter electromagnetic sounding of sea-ice thickness: Comparison of theoretical and field estimates, Geophysics, 60, 374-380, https://doi.org/10.1190/1.1443773, 1995.

Langhorne, P. J., Hughes, K. G., Gough, A. J., Smith, I. J., Williams, M. J. M., Robinson, N. J., Stevens, C. L., Rack, W., Price, D., Leonard, G. H., Mahoney, A. R., Haas, C., and Haskell, T. G.: Observed platelet ice distributions in Antarctic sea ice: An index for ocean-ice shelf heat flux, Geophys. Res. Lett., 42, 5442-5451, https://doi.org/10.1002/2015GL064508, 2015.

Leonard, G. H., Purdie, C. R., Langhorne, P. J., Haskell, T. G., Williams, M. J. M., and Frew, R. D.: Observations of platelet ice growth and oceanographic conditions during the winter of 2003 in McMurdo Sound, Antarctica, J. Geophys. Res., 111, C04012, https://doi.org/10.1029/2005JC002952, 2006.

Leonard, G. H., Langhorne, P. J., Williams, M. J. M., Vennell, R., Purdie, C. R., Dempsey, D. E., Haskell, T. G., and Frew, R. D.: Evolution of supercooling under coastal Antarctic sea ice during winter, Antarct. Sci., 23, 399-409, https://doi.org/10.1017/S0954102011000265, 2011.
Lewis, E. L. and Perkin, R. G.: The winter oceanography of McMurdo Sound, Antarctica, in Oceanology of the Antarctic Continental Shelf, Antarct. Res. Ser., edited by: Jacobs, S. S., pp. 145165, AGU, Washington, D.C., 1985.

McCrae, I. R.: A Summary of Glaciological Measurements Made Between 1960 and 1984 on the Mcmurdo Ice Shelf, Antarctica, Univ. of Auckland, Auckland, New Zealand, 1984.

Mahoney, A. R., Gough, A. J., Langhorne, P. J., Robinson, N. J., Stevens, C. L., Williams, M. J. M., and Haskell, T. G.: The seasonal appearance of ice shelf water in coastal Antarctica and its effect on sea ice growth, J. Geophys. Res., 116, C11032, https://doi.org/10.1029/2011JC007060, 2011.

Mundry, E.: On the interpretation of airborne electromagnetic data for the two-layer case, Geophys. Prospect., 32, 336-346, https://doi.org/10.1111/j.1365-2478.1984.tb00735.x, 1984.

Pfaffling, A. and Reid, J. E.: Sea ice as an evaluation target for HEM modelling and inversion, J. Appl. Geophys., 67, 242-249, https://doi.org/10.1016/j.jappgeo.2008.05.010, 2009.

Pfaffling, A., Haas, C., and Reid, J. E.: A direct helicopter EM sea ice thickness inversion, assessed with synthetic and field data, Geophysics, 72, F127-F137, 2007.

Price, D., Rack, W., Langhorne, P. J., Haas, C., Leonard, G., and Barnsdale, K.: The sub-ice platelet layer and its influence on freeboard to thickness conversion of Antarctic sea ice, The Cryosphere, 8, 1031-1039, https://doi.org/10.5194/tc-8-10312014, 2014.

Rack, W., Haas, C., and Langhorne, P. J.: Airborne thickness and freeboard measurements over the McMurdo Ice Shelf, Antarctica, and implications for ice density, J. Geophys. Res.-Oceans., 118, 5899-5907, https://doi.org/10.1002/2013JC009084, 2013.

Robinson, N. and Williams, M. J. M.: Iceberg-induced changes to polynya operation and regional oceanography in the southern Ross Sea, Antarctica, from in situ observations, Antarct. Sci., 24, 514-526, 2012.

Robinson, N. J., Williams, M. J. M., Stevens, C. L., Langhorne, P. J., and Haskell, T. G.: Evolution of a supercooled Ice Shelf Water plume with an actively growing subice platelet matrix, J. Geophys. Res.-Oceans, 119, 3425-3446, https://doi.org/10.1002/2013JC009399, 2014.

Rossiter, J. R. and Holladay, J. S.: Ice-thickness measurement, in: Haykin, S., Lewis, E. O., Rainey, R. K., and Rossiter, J. R. (Eds.): Remote Sensing of Sea Ice and Icebergs, John Wiley and Sons Inc., New York, NY, 141-176, 1994.

Smith, I. J., Langhorne, P. J., Haskell, T. G., Trodahl, H. J., Frew, R., and Vennell, R.: Platelet ice and the land-fast sea ice of McMurdo Sound, Antarctica, Ann. Glaciol., 33, 21-27, https://doi.org/10.3189/172756401781818365, 2001.

Sturm, M. and Holmgren, J.: An automatic snow depth probe for field validation campaigns, Water Resources Res., 54, 96959701, https://doi.org/10.1029/2018WR023559, 2018. 